\title{
Water vapor heterogeneity related to tropopause folds over the North Atlantic revealed by airborne water vapor differential absorption lidar
}

\author{
H. Flentje, A. Dörnbrack, G. Ehret, A. Fix, C. Kiemle, G. Poberaj, ${ }^{1}$ and M. Wirth \\ Deutsches Zentrum für Luft- und Raumfahrt Oberpfaffenhofen, Institut für Physik der Atmosphäre, Wessling, Germany \\ Received 26 April 2004; revised 17 November 2004; accepted 14 December 2004; published 15 February 2005.
}

[1] Airborne differential absorption lidar (DIAL) measurements of tropospheric water vapor and aerosol/clouds are presented from transfers across the North Atlantic on 13-15 May and 16-18 June 2002. The intense dynamical activity over the Atlantic is reflected in complex structures like deep tropopause folds, extended dry layers, and tilted aerosol filaments. Intrusions with $\mathrm{H}_{2} \mathrm{O}$ mixing ratios below $0.03 \mathrm{~g} \mathrm{~kg}^{-1}$ regularly develop along the storm track over intense cyclones and correspond to analyzed (European Centre for Medium-Range Weather Forecasts (ECMWF)) or simulated (MM5) potential vorticity anomalies. Sloping folds are typically $1 \mathrm{~km}$ thick in vertical profiles but on horizontal sections resemble long filaments with widths of a few hundred kilometers. Filaments of solid, roughly micron-sized particles occur inside and along the axes of the tropopause folds. The particles most likely originate in forest fires, from where they are injected to the lower stratosphere by deep convection and later on reenter the troposphere in developing baroclinic disturbances. Their laminar appearance indicates that these intrusions have not yet been mixed but are eroded on timescales significantly larger than a few days by stretching-thinning, stirring, and only finally, turbulent diffusion. MM5 mesoscale model simulations and, with less accuracy, also ECMWF analyses are capable of reproducing the dynamical structures associated with the observed dry intrusions. However, deep inside the intrusions where scales are small, even the MM5-simulated water vapor mixing ratios are more than twice those observed. The large dynamical range of water vapor mixing ratios ( 3 orders of magnitude) and large gradients $\left(>2 \mathrm{~g} \mathrm{~kg}^{-1} \mathrm{~km}^{-1}\right.$ at the intrusions' boundaries) constitute a challenge for future space-borne water vapor DIAL systems.

Citation: Flentje, H., A. Dörnbrack, G. Ehret, A. Fix, C. Kiemle, G. Poberaj, and M. Wirth (2005), Water vapor heterogeneity related to tropopause folds over the North Atlantic revealed by airborne water vapor differential absorption lidar, J. Geophys. Res., 110, D03115, doi:10.1029/2004JD004957.

\section{Introduction}

[2] Water vapor is the most important greenhouse gas [Möller, 1963; Manabe and Weatherald, 1967; Shine and Sinha, 1991]. The latent heat exchange due to its phase changes affects the vertical stability of the atmosphere, controls cloud formation [e.g., Kiehl and Trenberth, 1997; Koop et al., 2000; Kärcher and Haag, 2004], and the evolution of weather systems, making $\mathrm{H}_{2} \mathrm{O}$ crucial for the energy balance of the global climate system [e.g., Chahine, 1992; Jensen and Pfister, 2004]. Relative humidity controls radiative and chemical properties of aerosols and $\mathrm{H}_{2} \mathrm{O}$ is the prime source of atmospheric hydroxyl radicals. Water vapor plays a key role in removing both, particles and oxidized trace gases from the atmosphere. The

\footnotetext{
${ }^{1}$ Now at Eidgenössische Technische Hochschule, Zürich, Institute for Quantum Electronics, Zürich, Switzerland.

Copyright 2005 by the American Geophysical Union. 0148-0227/05/2004JD004957
}

fundamental role of moist processes in the atmosphere stands vis-à-vis to only $2 \%$ mass fraction of water vapor in the atmosphere. Its concentration in space and time varies over 4 orders of magnitude and therefore is difficult to measure with the required precision, resolution and temporal and spatial coverage. Thus monitoring water vapor with high accuracy, especially in the upper troposphere and lower stratosphere (UT/LS) region and in remote areas remain important scientific or technological issues.

[3] In spite of its relevance, water vapor is one of the least accurate parameters in the data assimilation for numerical weather prediction (NWP) models, due to the lack of global coverage accurate $\mathrm{H}_{2} \mathrm{O}$ observations. Most operational NWP analyses are based on lower and middle tropospheric humidity from regular radiosonde soundings, which are presently the only technique to provide vertical water vapor profiles routinely. However, assimilation schemes exclusively use data for pressures $p>300 \mathrm{hPa}$ [Elliott and Gaffen, 1991; Leiterer et al., 1997] as the sensors do not provide reliable water vapor at higher 
altitudes or in dry regions $<0.0622 \mathrm{~g} \mathrm{~kg}^{-1}$ (100 ppmv) (Conversion of water vapor mixing ratio is $\mathrm{w}_{\mathrm{H} 2 \mathrm{O}}\left[\mathrm{g} \mathrm{kg}^{-1}\right]=$ $\varepsilon \times 10^{-3} \times \mathrm{w}_{\mathrm{H} 2 \mathrm{O}}[\mathrm{ppmv}], \mathrm{w}_{\mathrm{H} 2 \mathrm{O}}$ being the mixing ratio in $\mathrm{g} \mathrm{kg}^{-1}$ or ppmv, respectively, and $\varepsilon=0.622$ being the ratio of molecular mass of water vapor to dry air. $\left(1 \mathrm{~g} \mathrm{~kg}^{-1} \equiv\right.$ 1608 ppmv.)). Moreover, major "birth" regions of severe continental weather (e.g., sensitive regions along the Atlantic or Pacific storm tracks and at the east coasts of North America or Asia) to which the short-term forecast errors are most sensitive are only covered by a few radiosonde stations [see Marseille and Bouttier, 2001]. The assimilation of satellite data [Moreau et al., 2003], which usually contain water vapor information between 200 and $500 \mathrm{hPa}$ at relatively low spatial resolution, also cannot reduce the background humidity error significantly below the range of $20-50 \%$ with tendency to even larger errors in regions with large spatial gradients, since complicated inversion procedures (retrievals) and manifold parameterizations have to be applied. Meteorological services thus consider adding new techniques to their assimilation like GPS occultation [Kursinski et al., 1996] or active remote sensing by radar and lidar.

[4] The idea to acquire global water vapor fields operationally with high spatial resolution and accuracy by a space-borne water vapor DIAL has been proposed to the European Space Agency (ESA) as an "Earth explorer core mission" namely WALES (Water Vapor Lidar Experiment in Space). A multiwavelength DIAL can continuously measure water vapor throughout the troposphere, even through kilometer-scale cloud gaps in overcast regions and reach NWP impact requirements as defined by the World Meteorological Organization [World Meteorological Organization, 2000; Gérard et al., 2004]. An assessment of the expected data quality and coverage of WALES under real atmospheric conditions, with observed horizontal and vertical $\mathrm{H}_{2} \mathrm{O}$ gradients as well as attenuating clouds and aerosols, therefore is an important task preceding the design of a space-borne $\mathrm{H}_{2} \mathrm{O}$ DIAL. To this end, data has been collected during two transfers across the northern and middle Atlantic by an airborne $\mathrm{H}_{2} \mathrm{O}$ /aerosol-DIAL, profiling the entire troposphere during a late Northern Hemisphere (NH) spring period. The dominant features observed along the Atlantic storm track are horizontal/vertical variability, sharp $\mathrm{H}_{2} \mathrm{O}$ gradients and extended aerosol filaments, associated with stratospheric intrusions.

[5] Stratosphere-troposphere exchange (STE), the flux of air and trace constituents across the tropopause, has been extensively investigated since the mid sixties. Danielsen [1968] described how the transverse (cross-jet stream) Sawyer-Eliassen circulation dynamically forms an upper level front along the core of a jet stream. At the rear of large-scale baroclinic disturbances stratospheric tracers are transported southward and downward along strongly tilted isentropes and subsequently extrude as tropopause folds, which can be mixed down by subsynoptic-scale turbulent processes within a few days. Signatures of stratospheric intrusions (low relative humidity $(\mathrm{RH})$ and high $\mathrm{O}_{3}$, radioactivity $\left({ }^{7} \mathrm{Be},{ }^{10} \mathrm{Be} /{ }^{7} \mathrm{Be}\right)$, static stability or potential vorticity (PV)) into the troposphere have been reported in many cases, based on $\mathrm{RH}$ or $\mathrm{O}_{3}$ balloon soundings, high-altitude ground station observations [e.g., Elbern et al., 1997], aircraft-borne in situ $\mathrm{RH}, \mathrm{O}_{3}$ /tracer measurements [e.g.,
Fabian and Pruchniewicz, 1977; Marenco et al., 1998, and references therein; Ovarlez et al., 1999] and remote sensing by satellite-borne [e.g., Wimmers et al., 2003] and lidar systems, both ground based [e.g., Ancellet et al., 1994; Eisele et al., 1999; Stohl and Trickl, 1999; Trickl et al., 2003; Zanis et al., 2003] and in aircraft [Browell et al., 1987; Ehret et al., 1999]. Model-aided meteorological analysis revealed in detail the bulk of underlying dynamical processes [e.g., Appenzeller and Davies, 1992; Wirth, 1995; Appenzeller et al., 1996b], their global-scale impact [Holton et al., 1995; Schoeberl, 2004, and references therein] and the fate of the intruded air masses [Shapiro, 1980; Appenzeller et al., 1996a; Wirth and Egger, 1999]. In spite of large scientific progress, the actual mass exchange between the stratosphere and the troposphere is still unsure. With respect to ozone, estimated influxes for single events are of the order of $5 \times 10^{32} \mathrm{O}_{3}$ molecules $\mathrm{d}^{-1}$, i.e., up to $2 \times 10^{33} \mathrm{O}_{3}$ molecules during a 2- to 4-day episode [e.g., Ancellet et al., 1994; Langford et al., 1996]. However, while tropopause folds bring air downward on the cyclonic side of the jet during the baroclinic growth phase, the fold retracts back into the stratosphere during the decay phase carrying some of the air with it. The residence of the intruded air in the troposphere [see Schoeberl, 2004, and references therein] thus remains an important issue.

[6] Most experimental studies of intrusions either refer to high resolution in situ $\mathrm{O}_{3}$ - and $\mathrm{H}_{2} \mathrm{O}$-, lidar $\mathrm{O}_{3}$-observations or low-resolution satellite measurements of water vapor. Presently, only two airborne lidar systems have measured water vapor at upper tropospheric concentrations as low as inside stratospheric intrusions: the Lidar Atmospheric Sensing Instrument (LASE) of NASA Langley Research Center [Browell et al., 1998], and the German Aerospace Center (DLR) water vapor DIAL [Ehret et al., 1999]. The latter is capable to measure even stratospheric water vapor mixing ratios of a few parts per billion with an accuracy of about 10-20\% [Hoinka et al., 2003]. Only few of the currently developed airborne or groundbased $\mathrm{H}_{2} \mathrm{O}$ lidars will have the potential to measure water vapor in UT/LS air [e.g., Trickl and Vogelmann, 2004].

[7] To our knowledge, the observations presented in this paper are the first water vapor cross sections along the entire North and middle Atlantic storm track. They provide highly resolved snapshots of different baroclinic scenes in this synoptically important region over a one week period. Due to the representative meteorological conditions during the flights, the different cases are appropriate to study the dynamical processes in great detail. Direct observations of the coherent multiple folds across the entire troposphere, as presented here, are rare. The paper's main objective is to present the extended DIAL water vapor/particle profiles in their meteorological context with particular emphasis on the observed tropopause folds. Thereby, European Center for Medium Range Weather Forecast (ECMWF) analyses and MM5 mesoscale model simulations are utilized. Section 2 briefly describes the experiment, the DIAL, the meteorological auxiliary tools and the data evaluation. Section 3 discusses the observed $\mathrm{H}_{2} \mathrm{O}$ structures in context with the meteorological situation, stratosphere-troposphere exchange and 

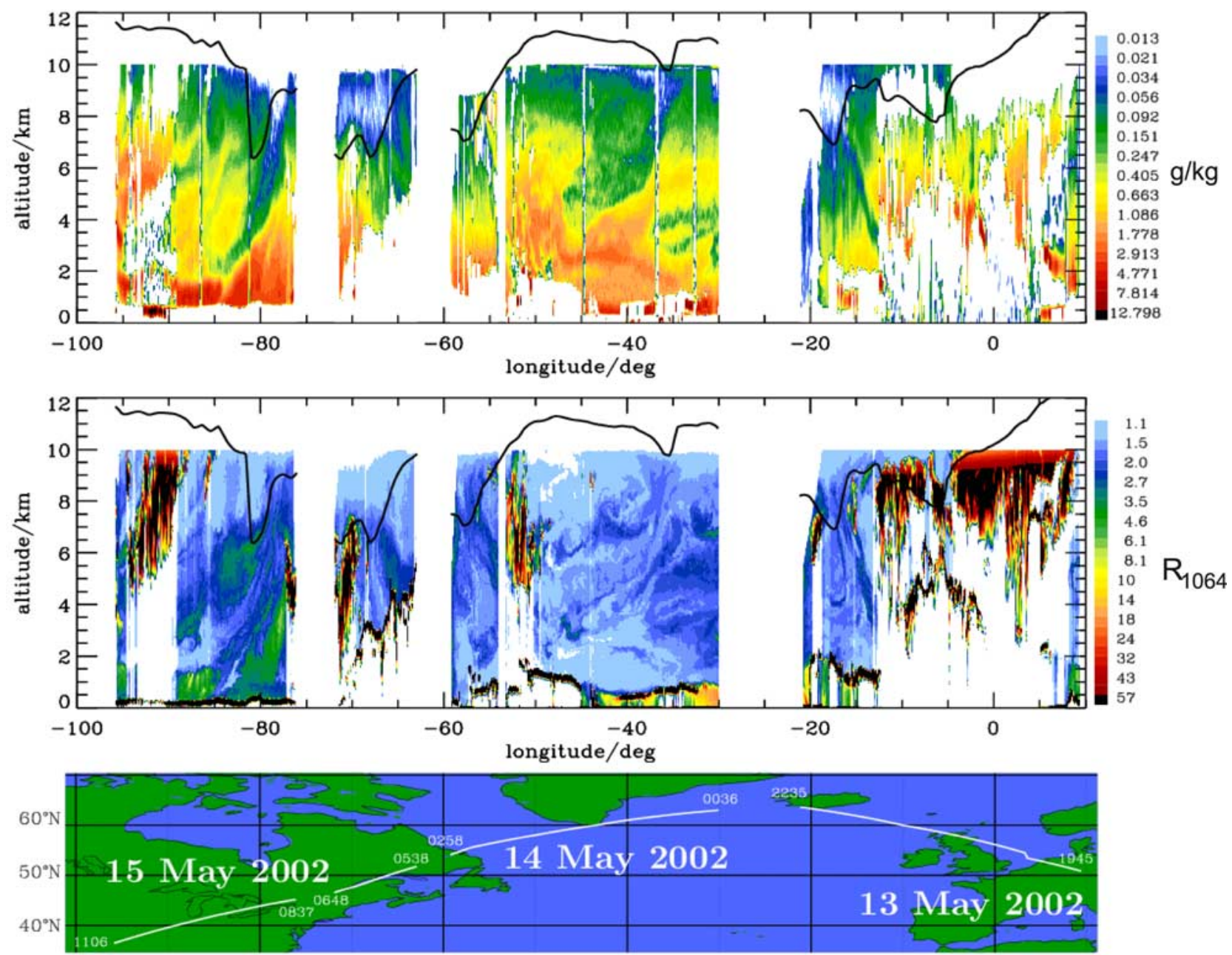

Figure 1. (top) Water vapor mixing ratio and (middle) backscatter ratio at $1064 \mathrm{~nm}$ along the westbound transfer from Germany to Oklahoma (United States) on 13-15 May 2002. Black lines mark the dynamical tropopause (2 PVU contour; 1 PVU $=10^{-6} \mathrm{~m}^{2} \mathrm{~s}^{-1} \mathrm{~K} \mathrm{~kg}^{-1}$ ), based on operational T511L60 ECMWF analyses (valid 14 May 0000 UTC for segments east of $60^{\circ} \mathrm{W}$ and 15 May 0600 UTC for segments west of $60^{\circ} \mathrm{W}$ ). (bottom) DLR Falcon flight legs with start and stop times in UTC. Note that due to the strong horizontal compression of the panels, typical "steep" intrusions actually have aspect ratios (horizontal scale $L$ to vertical scale $Z$ ) about $L / Z \approx 50$.

the particle observations. Section 4 summarizes the results and gives implications for space-borne $\mathrm{H}_{2} \mathrm{O}$-DIALs.

\section{Experimental and Diagnostic Tools}

\subsection{Transfer Flights}

[8] The DLR Falcon participation in the International $\mathrm{H}_{2} \mathrm{O}$ Project (IHOP) campaign from mid-May to mid-June in Oklahoma (central United States) involved the transit flights where tropospheric water vapor and aerosol backscatter ratio across the northern and middle Atlantic Ocean was measured. The transfers were performed from 13 to 15 May $2002(\mathrm{E} \rightarrow \mathrm{W})$ and from 16 to 18 June $2002(\mathrm{~W} \rightarrow \mathrm{E})$ and went from Germany to Oklahoma via Iceland, Greenland and Canada (westbound ferry) and from Oklahoma to Germany via Maine (United States), the Azores and Spain (eastbound ferry) as shown in Figures 1 (bottom) and 2 (bottom). Following the sun, the westbound measurements mostly took place in the dark at low solar zenith angles while the eastward transit flights were predominantly performed during daylight conditions. The typical flight level was $34,000 \mathrm{ft}$ (about $10 \mathrm{~km}$ altitude) and the total flight time for both transfers $(\approx 18,000 \mathrm{~km})$ was $\sim 26$ hours.

\subsection{Water Vapor DIAL}

[9] For the IHOP campaign the DLR water vapor DIAL [Poberaj et al., 2002] has been installed onboard the DLR research aircraft Falcon 20E (http://www.dlr.de/FB/OP) in nadir viewing arrangement. The transmitter is based on a Nd:YAG pumped, injection seeded KTP-OPO (Optical Parametric Oscillator). The Nd:YAG laser is operated in the single longitudinal mode with $220 \mathrm{~mJ}$ per pulse at $100 \mathrm{~Hz}$. Half of the fundamental output at $1064 \mathrm{~nm}$ is converted to the second harmonic, serving as the pump for the OPO, which produces $18 \mathrm{~mJ}$ per pulse at $925 \mathrm{~nm}$. The 

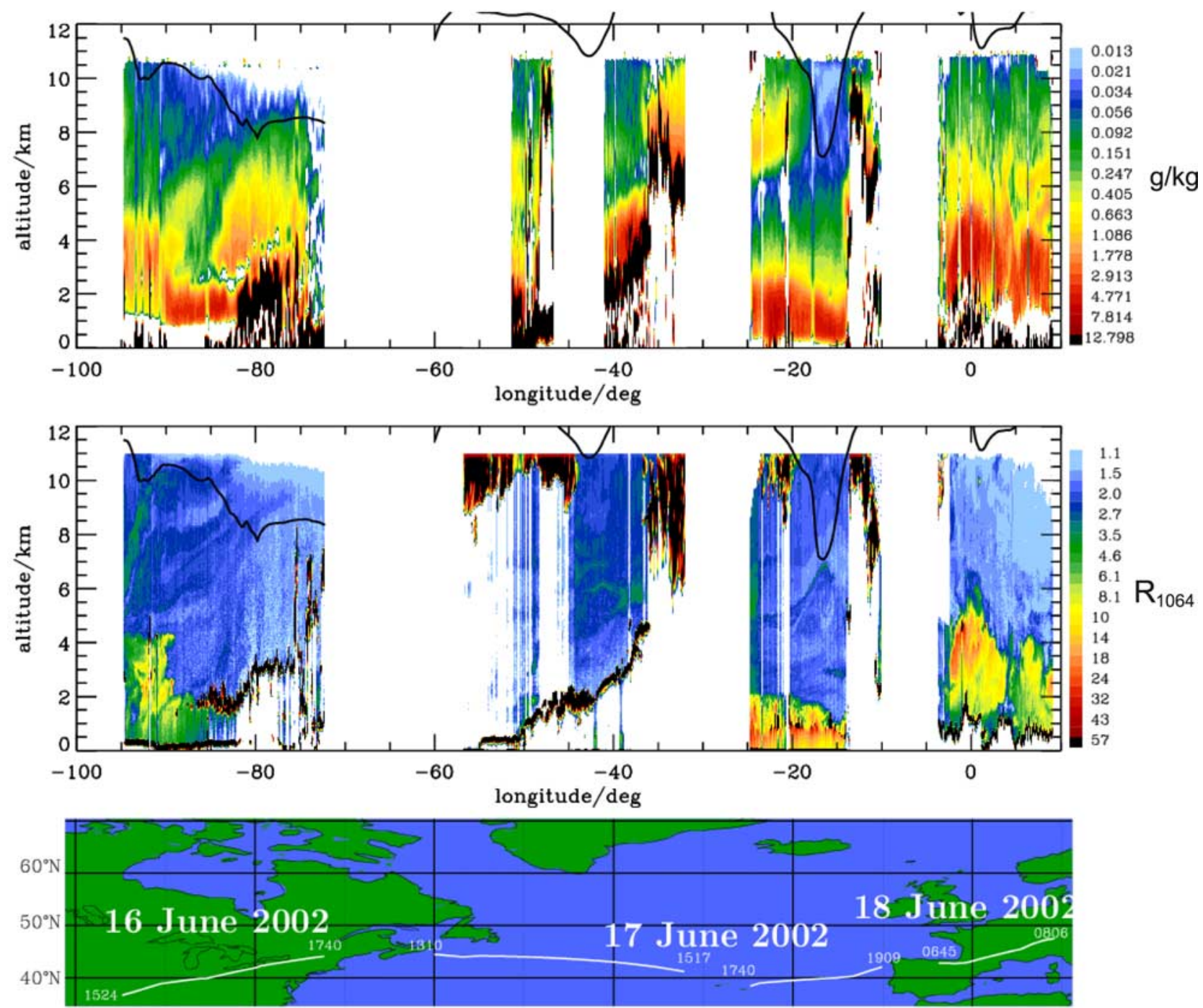

Figure 2. (top) Water vapor mixing ratio $\left(\mathrm{g} \mathrm{kg}^{-1}\right)$ and (middle) backscatter ratio at $1064 \mathrm{~nm}$ along the eastbound transfer from Oklahoma (United States) to Germany on 16-18 June 2002. Black lines mark the dynamical tropopause (2 PVU contour), based on operational T511L60 ECMWF analyses (valid 16 June $1800 \mathrm{UTC}$ for segments east of $60^{\circ} \mathrm{W}$ and 17 June $1800 \mathrm{UTC}$ for segments west of $60^{\circ} \mathrm{W}$ ). (bottom) DLR Falcon flight legs.

remaining pump laser radiation is used for atmospheric backscatter measurements. A spectral purity of more than $99 \%$ is mostly achieved during in-flight operation; the online frequency is controlled for each shot by use of a water vapor absorption cell. Three locking loops maintain a stable wavelength operation, the exact wavelength information is later needed for the calculation of water vapor concentrations. The back-scattered photons are collected by a Cassegrain-type telescope with an aperture of $35 \mathrm{~cm}$ and a field of view of $2 \mathrm{mrad}$. The received radiation is split into separate polarization channels at $1064 \mathrm{~nm}$ and at $532 \mathrm{~nm}$ for the shape-resolved aerosol measurement and the on-line and offline signals at $925 \mathrm{~nm}$ for the water vapor measurement. Background radiation is suppressed by a $1 \mathrm{~nm}$ interference filter. Airborne measurements in the $925 \mathrm{~nm}$ spectral regions allow to cover the range of typical concentrations from the PBL to the upper troposphere with typical vertical and
Table 1. Water Vapor DIAL Data Coverage and Resolution

\begin{tabular}{lccc}
\hline \multicolumn{1}{c}{ Flight } & Time, UTC & $\begin{array}{c}\text { Horizontal } \\
\text { Resolution, } \\
\mathrm{km}\end{array}$ & $\begin{array}{c}\text { Vertical } \\
\text { Resolution } \\
\text { Top/Down, } \\
\mathrm{km}\end{array}$ \\
\hline Munich to Keflavik & 13 May, 1948-2224 & $2.2^{\mathrm{b}}$ & $0.5 / 0.3^{\mathrm{b}}$ \\
Keflavik to Goose Bay & 14 May, 0036-0252 & 2.3 & $0.5 / 0.4$ \\
Goose Bay to Montreal & 15 May, 0537-0644 & 4.5 & $1 / 0.4$ \\
Montreal to Oklahoma & 15 May, 0840-1015 & 2.3 & $0.5 / 0.2$ \\
Oklahoma to Bangor & 16 June, 1525-1730 & 13.7 & $2 / 1$ \\
Bangor to Azores & 17 June, 1430-1500 & 13.5 & $1 / 1$ \\
Azores to Santiago & 17 June, 1752-1845 & 13.6 & $1 / 0.5$ \\
Santiago to Munich & 18 June, 0654-0754 & 4.7 & $0.5 / 0.5$ \\
\hline
\end{tabular}

${ }^{\mathrm{a}}$ Resolution is chosen such that the average statistical error remains below $10 \%$.

${ }^{\mathrm{b}}$ Vertical resolution of aerosol/cloud data is always $30 \mathrm{~m}$, and horizontal resolution is a few hundred meters. 
horizontal resolutions of $100 \mathrm{~m}$ to $1 \mathrm{~km}$ and about 1 to $10 \mathrm{~km}$, respectively. Thereby, the downward-looking configuration has the important advantage of partial compensation of the range-dependent $\left(\mathrm{R}^{-2}\right)$ signal degradation by the nearly exponential increase of the $\mathrm{H}_{2} \mathrm{O}$ absorption in the far range (lower troposphere). Therefore this instrumental setup allows resolution of mesoscale structures and large humidity gradients in transition zones throughout the troposphere. A detailed assessment of the DLR DIAL measurement accuracy is given by Poberaj et al. [2002]. Uncertainties in the water vapor retrieval arise both from systematic and statistical errors. Main sources of systematic errors are the uncertainty in the determination of the water vapor absorption line cross section $(5 \%$ estimated uncertainty), laser spectral impurity $(1-2 \%)$, atmospheric temperature uncertainty $(<1 \%)$, and the Rayleigh-Doppler absorption line broadening $(<1.5 \%)$. The statistical error of a DIAL measurement is controlled by the horizontal and vertical data smoothing applied. The spatial resolution listed in Table 1 has been chosen such that the resulting statistical error at the discussed structures (e.g., intrusions) on average remains below $10 \%$, which represents a good compromise between data uncertainty and resolution degradation by smoothing.

[10] The aerosol optical properties are expressed in terms of the particle backscatter ratio, defined as the total divided by the molecular backscatter coefficient $R_{\lambda}=\left(\beta_{\mathrm{p}, \lambda}+\beta_{\mathrm{m}, \lambda}\right) /$ $\beta_{\mathrm{m}, \lambda}\left(\lambda\right.$ denotes wavelengths), measured at $1064 \mathrm{~nm}\left(\mathrm{R}_{1064}\right)$ and $532 \mathrm{~nm}\left(\mathrm{R}_{532}\right)$. The color ratio $\mathrm{CR}=\beta_{532 \mathrm{~nm}} / \beta_{1064 \mathrm{~nm}}$ is an indicator for the effective radius of the optically dominant particles [Wirth et al., 1999]. From the parallel and perpendicularly polarized returns referred to the laser beam at 1064 and $532 \mathrm{~nm}$ the particle depolarization ratio $\delta_{\mathrm{p}, \lambda}=\beta_{\mathrm{p}, \lambda, \perp} / \beta_{\mathrm{p}, \lambda, \|}(\lambda=532$ or $1064 \mathrm{~nm})$ for the optically dominant particles is calculated as a measure of asphericity. The uncertainty of this derived quantity under free tropospheric conditions (low $\mathrm{R}_{1064 / 532}$ ) is roughly $30 \%$. In case of mixed phase clouds/aerosols, few nonspherical particles masked by numerous spherical ones may be detectable only by the sole perpendicular signal $\beta_{\mathrm{p}, \lambda, \perp}$. The backscatter-toextinction ratio (lidar ratio), inferred from inverting single profiles, contains some angular information on the scattering function and is also used to constrain the sizes of observed particles [Ackermann, 1998]. However, as the retrieval of particle properties depends critically on their (only appreciable) refractive index, the information on the particles remains qualitative or comprises large uncertainty [Müller and Quenzel, 1985]. The resolution of the backscatter measurements ranges from less than $100 \mathrm{~m}$ horizontally and a few tens of meters vertically in clouds and dense aerosols to roughly 10 times larger values at free tropospheric conditions, the overall uncertainty each being of the order of $3 \%$ for the backscatter coefficient.

\subsection{Meteorological Analyses and Mesoscale Simulations}

[11] The synoptic situations are characterized with the aid of T511/L60 operational analyses of the European Centre for Medium Range Weather Forecast (ECMWF). The analyses are interpolated onto a regular $0.5^{\circ} \times 0.5^{\circ}$ latitudelongitude grid. All the numerical simulations are performed with the fifth-generation Pennsylvania State University-
National Centre for Atmospheric Research (Penn StateNCAR) mesoscale weather prediction model MM5. The nonhydrostatic compressible model is used in its version V3.4.0 [Dudhia, 1993; Dudhia et al., 2001]. The upper boundary is set to $10 \mathrm{hPa}$, altogether 115 vertical levels are used (i.e., $\Delta \mathrm{z} \approx 250 \mathrm{~m}$ ). The horizontal grid size is $\Delta \mathrm{x}=$ $36 \mathrm{~km}$ and for some simulations a local grid refinement scheme with $\Delta \mathrm{x}=12 \mathrm{~km}$ has been applied. The simulations include parameterizations for moist processes [Reisner et al., 1998], convection [Grell et al., 1994] and the MRF planetary boundary layer parameterization of vertical diffusion [Hong and Pan, 1996]. Radiation effects are neglected. The model is initialized with ECMWF fields and the integration is forced by 6 hourly ECMWF analyses at the outer lateral boundaries. A modified upper boundary condition is used to prevent the reflection of gravity waves [Zängl, 2002].

\section{Results and Discussion}

\subsection{Meteorological Conditions}

[12] Figures $3 \mathrm{a}$ and $3 \mathrm{~b}$ depict the potential temperature $\Theta$ and the horizontal wind speed $V_{H}$ at the dynamical tropopause, here defined by the 2 PVU surface; 1PVU = $10^{-6} \mathrm{~m}^{2} \mathrm{~s}^{-1} \mathrm{~K} \mathrm{~kg}^{-1}$ (e.g., Holton et al. [1995] and Thorncroft et al. [1993], PV definitions of the dynamical tropopause in the literature range from 1.5 to $3.5 \mathrm{PVU}$ ). Large $\Theta$ values correspond to a high tropopause, small $\Theta$ values to a lower tropopause altitude. Large $\Theta$ gradients ("fronts") are related to a significant vertical increase in $\mathrm{V}_{\mathrm{H}}$ and define the location of the jet streams associated with these transition zones. Unlike constant-pressure charts, all tropopause-based jets appear here on one map (e.g., polar jet and subtropical jet). Due to the dominating south-north $\Theta$ gradient the jets are preferentially zonal oriented. Rossby waves appear as undulations of these gradients, and coherent vortices appear as regions of closed $\Theta$ contours [Morgan and Nielsen-Gammon, 1998], Northern Hemispheric tropopause maps based on ECMWF analyses are updated regularly at http://www.pa.op.dlr.de/ arctic.

[13] The period of the westbound ferry flights (1315 May 2002, Figure 3a) was characterized by a rapid cyclogenesis over the northeast of the United States (around $80^{\circ} \mathrm{W}, 45^{\circ} \mathrm{N}$ ) and above the Atlantic Ocean. The troughs appear as southward excursions of low $\Theta$ values, i.e., a low tropopause (stratospheric intrusions) accompanied by a strongly curved subtropical jet stream forming a nearly sinusoidal $\Theta$ and $\mathrm{V}_{\mathrm{H}}$ pattern from $90^{\circ} \mathrm{W}$ up to the Greenwich meridian on 15 May 2002 0000UTC. Other relevant features of this period are the persistent ridge above Greenland (tropopause height at about $240 \mathrm{hPa}$ ) and a mesocyclone stretching northward above the Norwegian Sea (tropopause height at about $540 \mathrm{hPa}$ ). For the eastbound ferry flights (16-18 June 2002, Figure 2 (bottom)) one month later, the meteorological situation has changed to summer-type conditions: larger $\Theta$ values (higher tropopause) extend further north and the meridional $\Theta$ gradients are generally less pronounced resulting in a weaker subtropical jet stream. However, an already existing Rossby wave over the Atlantic amplifies while propagating eastward during this short period. The amplification results in a deep low west of the British Isles and a significant south- 

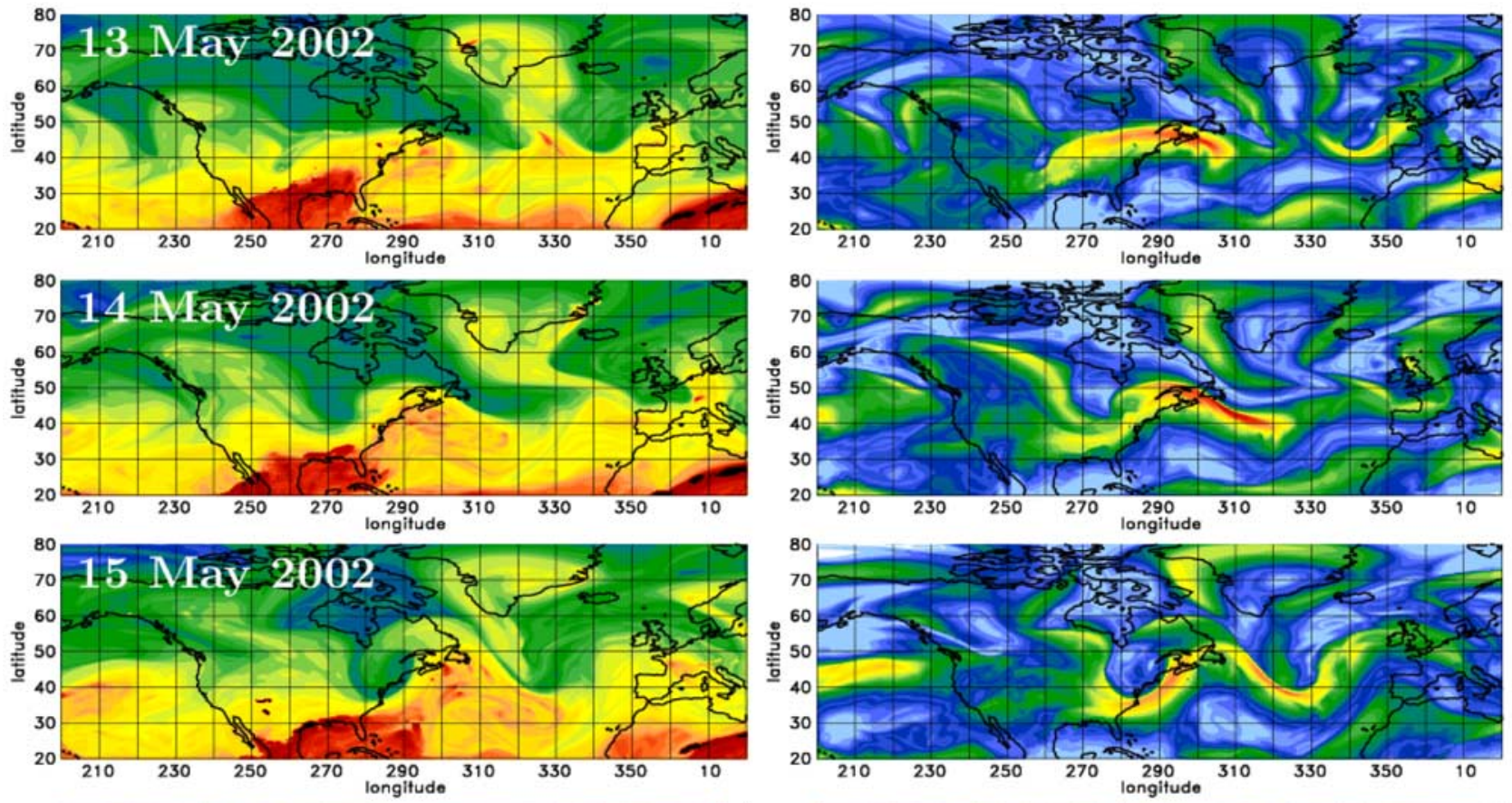

$\begin{array}{lllllllllllllll}274 & 282 & 290 & 298 & 306 & 314 & 322 & 330 & 338 & 346 & 354 & 362 & 370 & 378 & 386\end{array}$

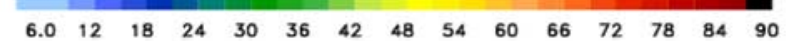

Figure 3a. Tropopause maps: (left) potential temperature $(\mathrm{K})$ and (right) horizontal wind speed $\left(\mathrm{m} \mathrm{s}^{-1}\right)$ at the dynamical tropopause (defined as 2 PVU surface) at the marked days valid at 0000 UTC from ECMWF T511L60 operational analyses. Longitude given in degrees east corresponds to ${ }^{\circ} \mathrm{W}+360^{\circ}$.
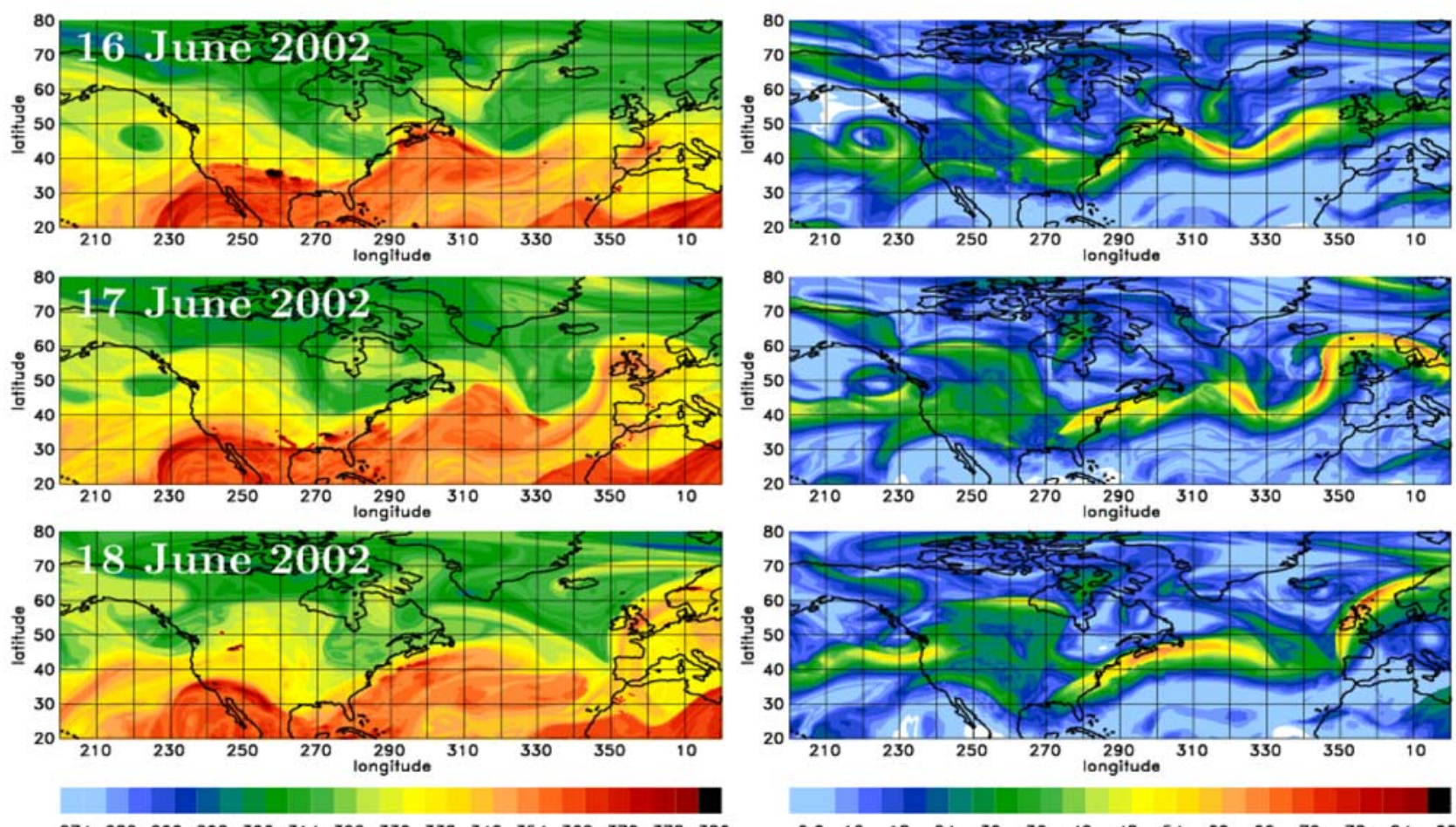

Figure 3b. Tropopause maps: (left) potential temperature (K) and (right) horizontal wind speed $\left(\mathrm{m} \mathrm{s}^{-1}\right)$ at the dynamical tropopause (defined as 2 PVU surface) at the marked days valid at $0000 \mathrm{UTC}$, as in Figure 3a. 
ward excursion of stratospheric air between the Azores and Spain.

[14] The first segment of the westbound ferry flights (Munich-Keflavik) intersected the southern branch of the mesoscale cyclone above the Norwegian Sea, the second one passed the anticyclone above Greenland, and the last two flight segments crossed the developing cyclone over North America while the final part of the flight region was dominated by a large anticyclone over the Midwest of the United States. The first eastbound ferry flight from Oklahoma City to Bangor, Maine encountered a similar, but weaker cyclone over the great lakes compared to the last westbound ferry flight. The second eastbound flight took place under nearly zonal flow conditions with small dynamical components whereas the third flight from the Azores to Spain passed the southern tip of the trough centered west of the British Isles. The meteorological conditions during the last flight were governed by a high-pressure system over central Europe. The corresponding ECMWF analyses or MM5 simulations are shown and discussed in more detail in the following subsections.

\subsection{Lidar Measurements}

[15] The westbound and eastbound transits of the DLR Falcon were split into 4 segments each. Both, the water vapor as well as the aerosol backscatter $R_{1064}$ section in Figures 1 and 2 exhibit large variability and complexity. The water vapor profiles are dominated by strong vertical gradients: high water vapor mixing ratios $\mathrm{q}>5 \mathrm{~g} \mathrm{~kg}^{-1}$ are mostly confined to altitudes less than $4 \mathrm{~km}$ and $\mathrm{q}$ in mean decreases exponentially with increasing altitude, hence logarithmic color scales are used for $\mathrm{r}$ and $\mathrm{R}_{1064}$, respectively. Only during the flight near the subtropics (17 June 2002 around the Azores) higher q values are measured at greater altitudes which are associated with rising thermals of deep convection. It must be noted that in some parts of the flights dense tropospheric clouds strongly attenuated the laser beam, and occasionally, the beam was even blocked. These regions without any backscatter signal below these clouds (and also without water vapor data) are left white in the q panels of Figures 1 and 2. An overview of the data coverage and resolutions at different flight segments is given in Table 1.

[16] The water vapor observations show several deep intrusions of dry upper tropospheric/lower stratospheric air into the mid and lower troposphere. The value of $\mathrm{q}=$ $0.0622 \mathrm{~g} \mathrm{~kg}^{-1}$ (100 ppmv) is used as an approximate threshold to separate tropospheric and stratospheric air [e.g., Ovarlez et al., 1999]. These intrusions exhibit manifold structure of different vertical extent and width. In Figures 1 and 2, the dry intrusions tilt westward in most of the cases: near $20^{\circ} \mathrm{W}, 40^{\circ} \mathrm{W}$ and $80^{\circ} \mathrm{W}$ on the westbound flights and around $85^{\circ} \mathrm{W}, 40^{\circ} \mathrm{W}$, and $20^{\circ} \mathrm{W}$ during the eastbound flights. However, as the aircraft heading always had a southerly or northerly component, the tilting direction is actually also north-southward. The only exception is a narrow filament which tilts to the opposite direction close to $15^{\circ} \mathrm{W}$ in Figure 1 (see section 3.2.1). The stratospheric $\mathrm{q}$ values observed in the tropopause folds extend to much lower altitudes than the 2 PVU surface in the ECMWF analyses.

[17] In the following subsections, selected cases are described in more detail, whereby the DIAL water vapor data is compared with MM5 simulations or ECMWF analyses. However, an in-depth interpretation of the details has to be postponed to a following publication. Here, basic findings along the transfer flights will be summarized, basically interpreted and the observations' potential to answer outstanding questions will be discussed.

\subsubsection{A Narrow Filament From a Mesocyclone,}

\section{May 2002}

[18] During most of the flight on 13 May 2002 from Germany toward Iceland via Scotland the DLR Falcon flew in and above thick cirrus clouds extending vertically down to about $6 \mathrm{~km}$ altitude (Figure 1). These compact cloud layers were associated with the warm sector of the depression system west of the UK (see the stratiform cloud band extending from UK toward Norway in the NOAA AVHRR imagery at 13 May 20021639 UTC and 14 May 2002 0218 UTC in http://www.sat.dundee.ac.uk). In the cloud layer the backscatter ratio increased up to $\mathrm{R}_{1064} \approx 100$ and although the laser beam was strongly attenuated and partly blocked, a few cloud gaps exceeding the horizontal averaging scale (compare to Table 1) allowed the detection of midtropospheric clouds. There, the water vapor distribution with typical midtropospheric values of $\mathrm{q} \approx 1 \mathrm{~g} \mathrm{~kg}^{-1} \approx$ 1607 ppmv could be determined between the upper and middle tropospheric clouds (see Figure 1). In the western part of this flight (from $10^{\circ} \mathrm{W}$ to $20^{\circ} \mathrm{W}$ ) the water vapor concentration dropped rapidly due to the postfrontal clearing. At low altitudes, broken stratocumulus clouds near the top of the PBL dominate the aerosol backscatter whereas at greater altitudes the backscatter ratio is rather low $\left(\mathrm{R}_{1064} \approx\right.$ 1...2) except in a few cirrus clouds detected below the dynamical tropopause. The most interesting feature of this low water vapor region is the eastward tilting narrow filament at $16^{\circ} \mathrm{W}$ extending down to about $3 \mathrm{~km}$ altitude.

[19] Figure 4 shows a close-up of this roughly $300 \mathrm{~km}$ long water vapor filament with a vertical depth of about $1500 \mathrm{~m}$. The water vapor mixing ratio ranges from less than $0.02 \mathrm{~g} \mathrm{~kg}^{-1}$ (30 ppmv) at the top to about $70 \mathrm{~g} \mathrm{~kg}^{-1}$ in the deepest parts of the filament. The mesoscale model simulation reproduces the shape and position of the observed filament with high accuracy (Figure 4). For this simulation a nested domain with $\Delta \mathrm{x}=12 \mathrm{~km}$ had to be used in order to simulate the dynamics properly. However, the very low water vapor mixing ratio inside the filament is not reproduced: at $4 \mathrm{~km}$ altitude the modeled water vapor mixing ratio is about 5 times larger than the DIAL measurements while the discrepancy is only a factor of two in the upper region. Clearly, the discrepancies between observations and MM5 simulations are larger deeper inside the fold, where the scales are significantly smaller, gradients are larger and different fluid-dynamical processes take over. How much the coarser spatial representation of the dynamical processes and to what extent the water vapor initialization procedure and the dynamical parameterization limit the simulation skill of the MM5 model can not be decided yet and must be postponed to a separate study.

[20] The underlying dynamical processes generating the narrow filament are simulated very well by the mesoscale model. According to the superimposed wind field, the filament is located in a region of strong vertical and horizontal shear separating two different air masses: wet air from the warm sector of the depression above the British 

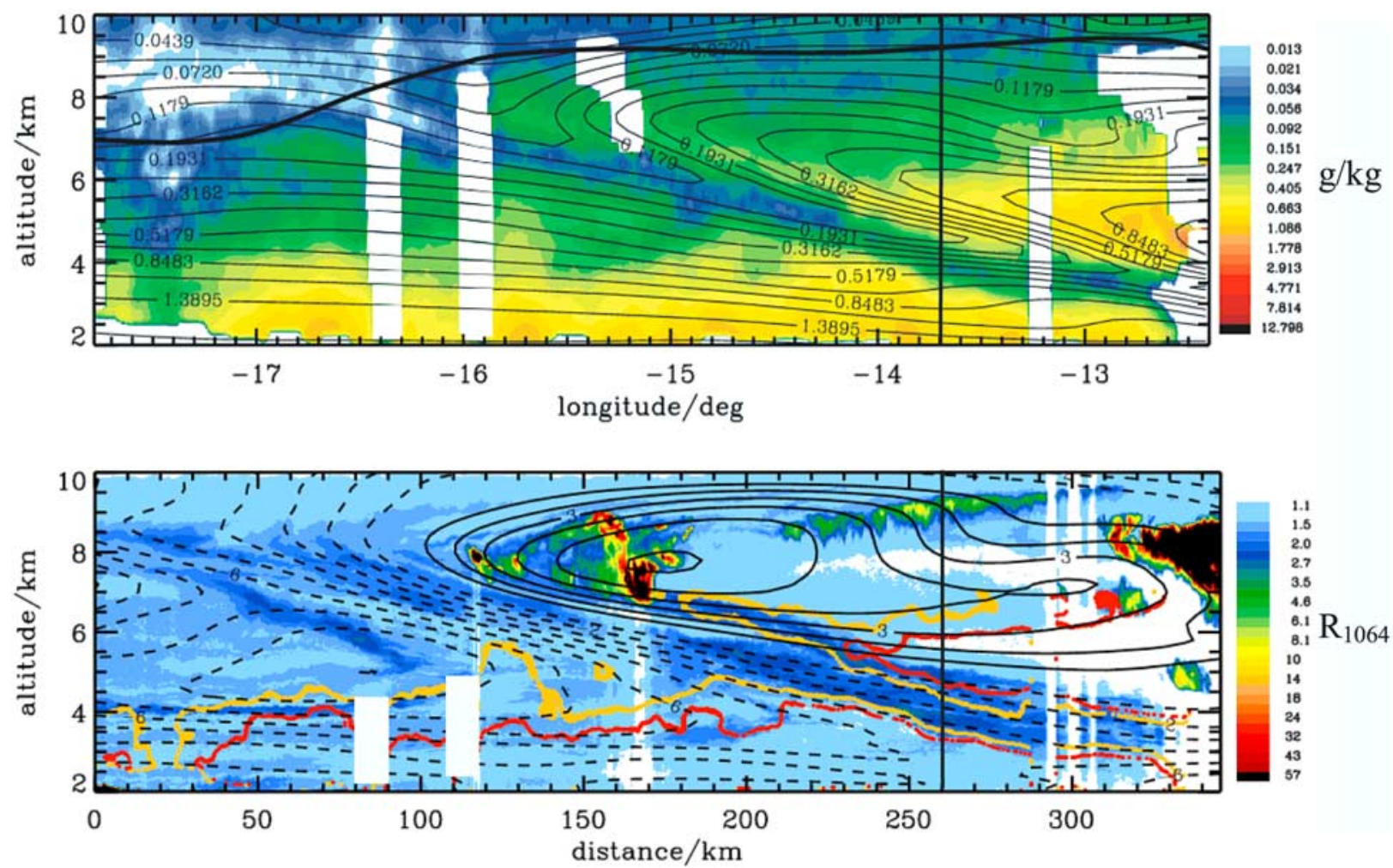

Figure 4. (top) DIAL water vapor mixing ratio with contours of simulated water vapor mixing ratio $\left(\mathrm{g} \mathrm{kg}^{-1}\right)$ by the MM5 mesoscale model and ECMWF dynamical tropopause (2 PVU surface) along flight leg 1 from Germany to Iceland on 13 May 1800 UTC. (bottom) Backscatter ratio at 1064 nm along same flight leg with contours of wind speed (dashed lines, wind directed out of the plane; solid lines, wind directed into the plane) and water vapor contours at 0.2 (orange) and $0.35 \mathrm{~g} \mathrm{~kg}^{-1}$ (red).

Isles sliding up and northward over colder descending air masses flowing south along the rear of the mesoscale cyclone over the Norwegian Sea. Figure 5 depicts the simulated horizontal water vapor distribution at two stages of the evolution of the mesocyclone between Iceland and
Norway. The timescale of the formation and meridional elongation of the mesocyclone is about 3 days whereas the narrow filament develops in just a couple of hours (Figure 5). Due to the ambient horizontal deformation the dry filament becomes horizontally stretched and elongated.
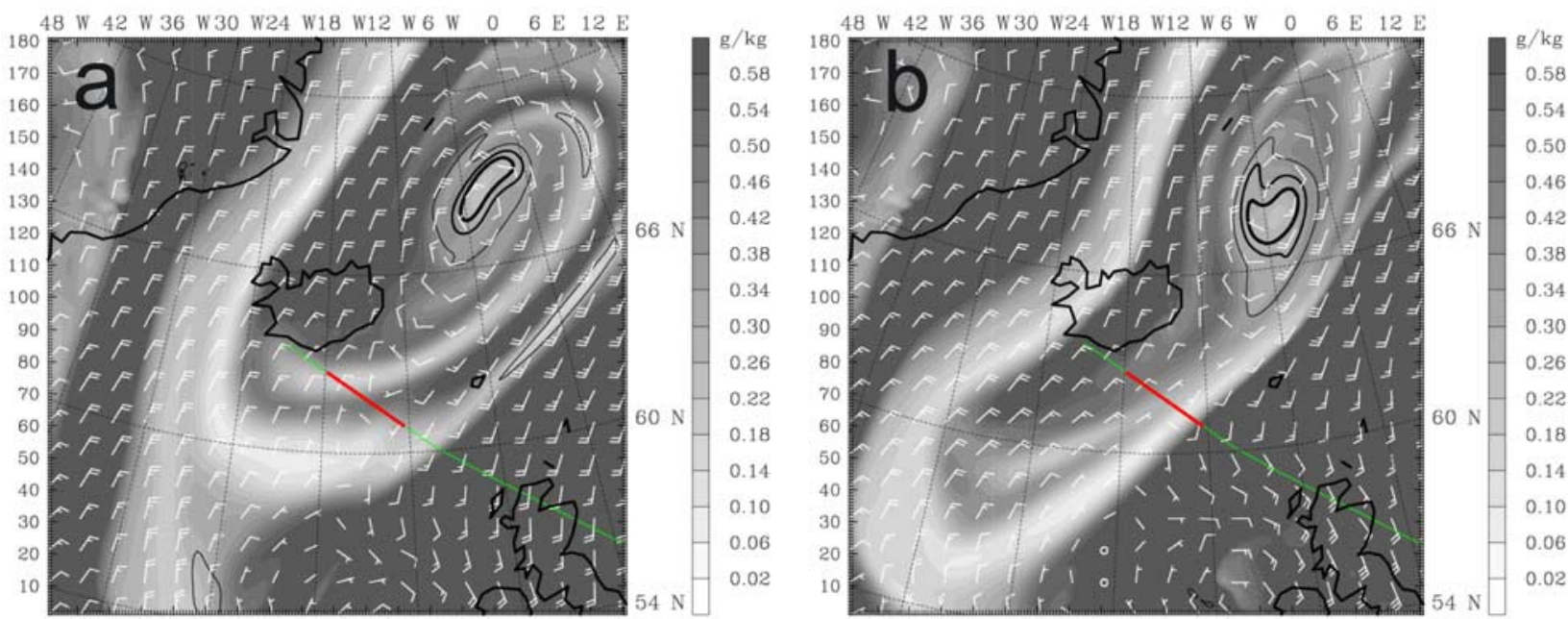

Figure 5. Simulated water vapor mixing ratio $\left(\mathrm{g} \mathrm{kg}^{-1}\right.$, color shaded), horizontal wind $\left(\mathrm{m} \mathrm{s}^{-1}\right.$; wind flags are as follows: small barbs, $5 \mathrm{~m} \mathrm{~s}^{-1}$; long barbs, $\left.10 \mathrm{~m} \mathrm{~s}^{-1}\right)$, and potential vorticity $(3.5,2.5$, and 1.5 PVU as thick, normal, and thin black lines) at $5 \mathrm{~km}$ altitude. (a) Valid time 13 May 2002, 1200 UTC (+12 hours since MM5 initialization) and (b) valid time 13 May 2002, 2200 UTC (+22 hours). Flight path of the DLR Falcon is marked in green; the segment shown in Figure 4 is in red. 


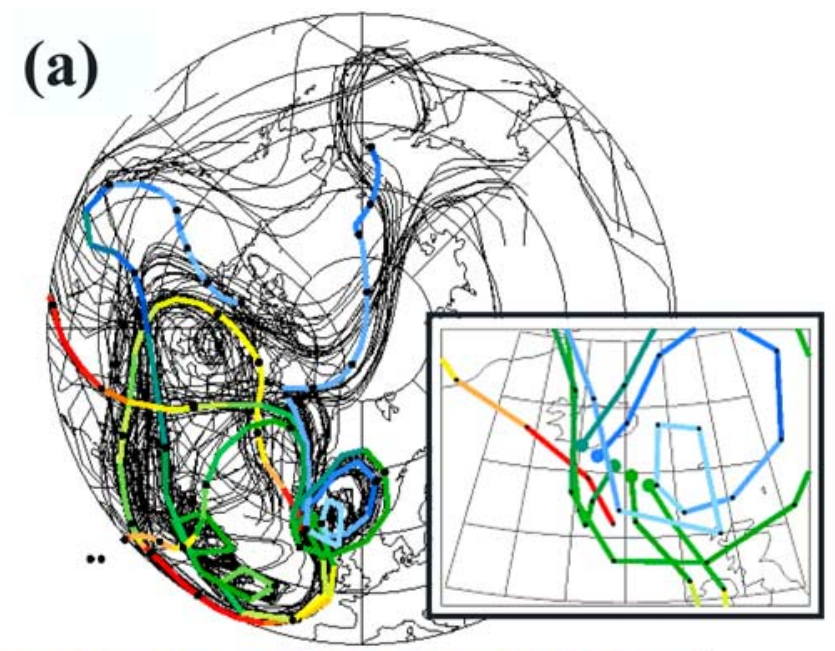

13. 21. 34. 56. $92.150 \quad 247 \quad 404 \quad 662 \quad 1085 \quad 1778291247707813 \quad 12798$

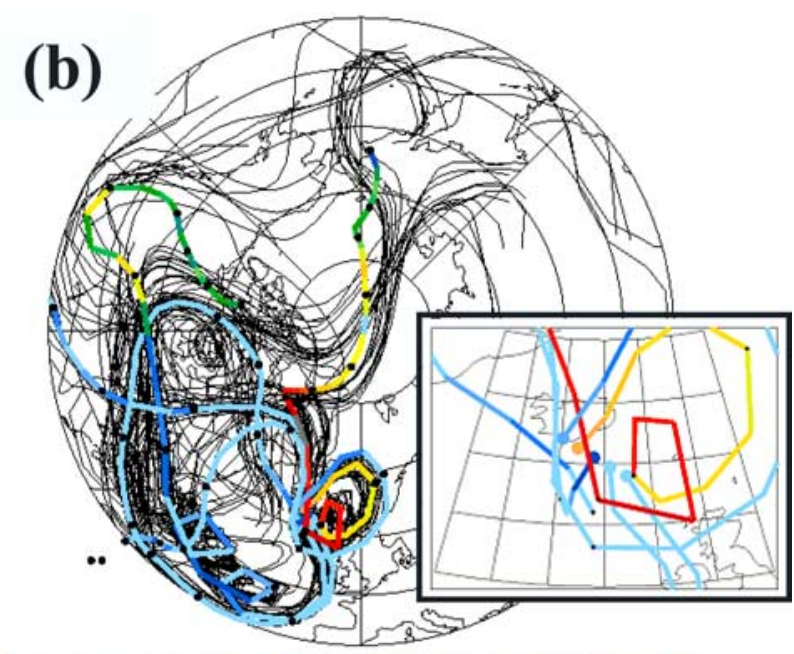

$\begin{array}{lllllllllllllll}0.4 & 0.8 & 1.2 & 1.6 & 2.0 & 2.4 & 2.8 & 3.2 & 3.6 & 4.0 & 4.4 & 4.8 & 5.2 & 5.6 & 6.0\end{array}$

Figure 6. Ten-day ECMWF backward trajectories arriving at $350 \mathrm{hPa}$ in a region between Scotland and Iceland on 14 May 2002, 0000 UTC. (a) Water vapor mixing ratio $\left(\mathrm{mg} \mathrm{kg}^{-1}\right)$ and (b) potential vorticity (PVU). Air parcel trajectories arriving close to the DLR Falcon flight path are color shaded in the hemispheric as well as in the close-up panels.

Ten days backward trajectories, run with the code LAGRANTO [Wernli and Davis, 1997] and based on ECMWF analyses, confirm the stratospheric origin of the air inside the filament (Figure 6). The dry and high-PV air parcels associated with the filament originate from the high Arctic and hovered around the tropopause for at least 10 days as indicated by the variation of the PV along the trajectories. Only during the last two days before the observation, the air masses descend rapidly to their arrival points at $350 \mathrm{hPa}$. Thus it is the combined horizontal deformation and the spiral cyclonic descent of the dry stratospheric air parcels that result in the narrow filament measured by the water vapor DIAL. The analysis of this particular event reveals that the descent of stratospheric air goes along with significant vortex stretching. The resulting elongation and fragmentation of water vapor filaments and their fine-scale structure are a prerequisite for the consequent irreversible exchange of air between the stratosphere and troposphere [e.g., Appenzeller and Davies, 1992; Appenzeller et al., 1996a]. The large water vapor and aerosol backscatter gradients at the filament boundary indicate that mixing strongly lags the filament generation as the folds are stabilized by their inherent stratospheric stratification. According to quasi-geostrophic scaling considerations, tracer sheets exposed to horizontal strain with rate $\Gamma$ combined with vertical shear $\Lambda$ are tilted to the horizontal at an angle $\Psi=\arctan (\Gamma / \Lambda)$ and reduce in horizontal and vertical thickness as $\mathrm{L}(\mathrm{t}) \sim \mathrm{e}^{-\Gamma \mathrm{t}}$ and $\mathrm{D}(\mathrm{t})=$ $\mathrm{L}(\mathrm{t}) * \Gamma / \Lambda$ [Haynes and Anglade, 1997], respectively. The observed angle of the fold results in $\Gamma / \Lambda>5 * 10^{-4}$ since the fold may be steeper when crossed perpendicularly. The value of $\Gamma \approx 10^{-3}-10^{-4} \mathrm{~s}^{-1}$ (base top) at the fold's boundary (Figure 4) corresponds to an $\mathrm{e}^{-1}$-folding timescale of a few hours to one day for spatial scales implying a "mix-down" time of $\sim 4$ days for the lower parts of the fold to reduce from initial horizontal scales of $50 \mathrm{~km}$ to about $1 \mathrm{~km}$ (a few tens of meters vertical), where molecular and turbulent diffusion microscopically mix the air masses. The exact mixing rate at the filament's boundary and the question of permanent residence of the injected air in the troposphere can not be deduced from the water vapor data alone and will be subject of a later model-based study.

[21] Figure 4 (bottom) details the aerosol distribution associated with the intrusion. In the vertical, the locations of the aerosol filaments fit exactly to those of the low water vapor mixing ratio. Note the lower vertical resolution of the water vapor data, $\Delta \mathrm{z}_{\mathrm{H} 2 \mathrm{O}} \approx 0.7 \mathrm{~km}$ compared to $\Delta \mathrm{z}_{\mathrm{aerosol}} \approx$ $0.03 \mathrm{~km}$. They extend down to about $3 \mathrm{~km}$ altitude. At the upper part, the aerosol filament seems to be connected to cirrus clouds and an aerosol layer at $8 \mathrm{~km}$ close to the ECMWF dynamical tropopause. Though their backscatter ratio $\mathrm{R}_{1064} \approx 2-4$ (variable), color ratio $\mathrm{CR} \approx 1.8 \pm 0.2$ and particle depolarization ratio $\delta_{\mathrm{p}, 1064} \approx 0.11 \pm 0.03$ are quite well known, T-Matrix calculations [Mishchenko, 1991], can not be applied because of large uncertainties in the particles' (sometimes fractal) shape and their composition.

\subsubsection{Low Water Vapor Tongue Above Greenland,}

14 May 2002

[22] During the flight from Iceland to Goose Bay (Canada) via Greenland on 14 May 2002 the Falcon intercepted the southern edge of the high pressure ridge above Greenland (Figure 3a). Correspondingly, the observed backscatter distribution only contains a stratocumulus layer at a height of about $1 \mathrm{~km}$ and a few cirrostratus clouds toward the end of the flight when a trough over Canada was approached (see the descending ECMWF dynamical tropopause in Figure 1). A common feature occurs in the middle of the flight in both aerosol and water vapor: an intrusion-like pattern of dry air, a tongue of low water vapor mixing ratios of $\mathrm{q} \approx 0.1 \ldots 0.3 \mathrm{~g} \mathrm{~kg}^{-1}$ near the southern tip of Greenland. The structure bends down to $3 \mathrm{~km}$ altitude and tilts westward with decreasing height. At its boundaries the mixing ratio increases to values $\mathrm{q}>0.5 \mathrm{~g} \mathrm{~kg}^{-1}$. Along 
(a)

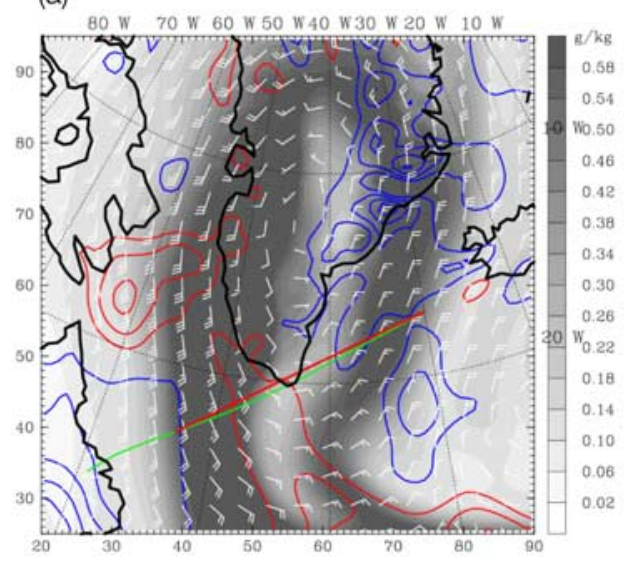

(b)

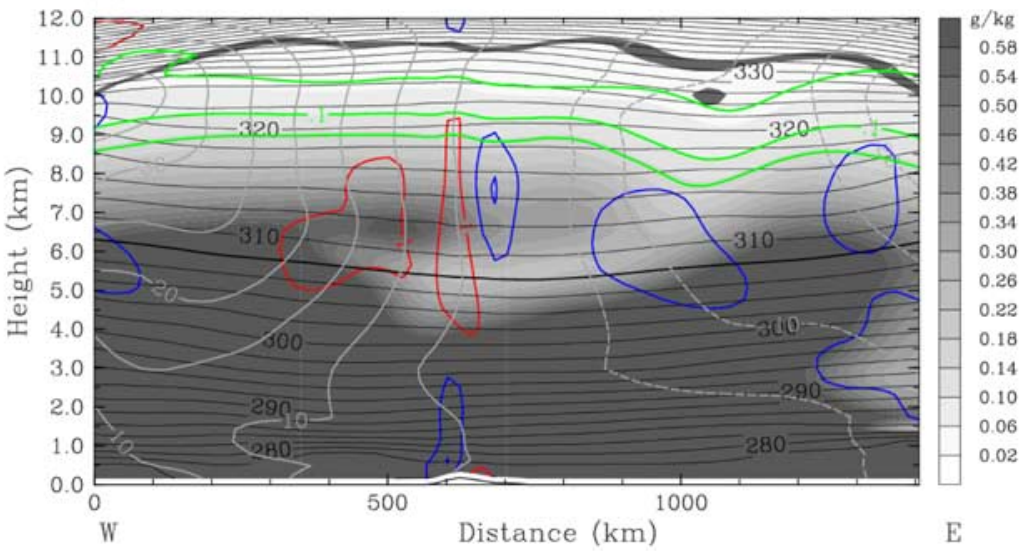

Figure 7. (a) Simulated water vapor mixing ratio $\left(\mathrm{g} \mathrm{kg}^{-1}\right.$, shaded), horizontal wind speed $\left(\mathrm{m} \mathrm{s}^{-1}\right.$; small barbs, $5 \mathrm{~m} \mathrm{~s}^{-1}$; long barbs, $10 \mathrm{~m} \mathrm{~s}^{-1}$ ), and vertical wind ( $\mathrm{cm} \mathrm{s}^{-1}$; red, positive; blue, negative; increment, $1 \mathrm{~cm} \mathrm{~s}^{-1}$ ) at $308 \mathrm{~K}$ surface valid on 14 May 2002, 0100 UTC (+13 hours since MM5 initialization). Left and lower axes provide distance; one minor tick $\equiv 36 \mathrm{~km}$. (b) Vertical section along the red line in Figure 7a. Additional fields are the section normal wind speed $\left(\mathrm{m} \mathrm{s}^{-1}\right.$; solid gray lines, wind into the plane; dashed gray line, wind out of the plane), potential temperature ( $\mathrm{K}$, solid black lines), and the tropopause marked by the gray $2-2.5 \mathrm{PVU}$ ribbon between 10 and $11 \mathrm{~km}$. Water vapor mixing ratios of $0.05,0.10$, and $0.15 \mathrm{~g} \mathrm{~kg}^{-1}$ are highlighted in green.

the whole flight segment the ECMWF tropopause is higher than $10 \mathrm{~km}$ and its profile does not indicate a deep intrusion responsible for the dry air in the mid and lower troposphere (Figure 1). ECMWF analyses suggest, that the observed structure is not caused by vertical descent as occurring in folds, but by quasi-horizontal (isentropic) transport.

[23] This hypothesis is supported by the simulated water vapor distribution (Figure 7). The mesoscale simulations show advection of moist subtropical air along the western side of Greenland toward north at the $308 \mathrm{~K}$ isentrope (which is the central $\Theta$ of this feature). Due to the anticyclonic flow, the moist air returns on the eastern side of the island forming a horseshoe-like pattern above Greenland. Selected ECMWF backward trajectories arriving along the flight track of the Falcon also show that the moist air on the western and eastern side of Greenland originates from midlatitudes (Figure 8). However, their individual history is different: whereas the air parcel arriving on the eastern side traveled the long way around the island while descending and warming, the western counterparts spiral up and cool. The vertical displacements of the parcels are very slow; the simulated vertical velocities are of the order of $1 \mathrm{~cm} \mathrm{~s}^{-1}$ (see Figure 7). Parcels arriving at the dry end points of the selected trajectories also descend, but their paths are essentially confined in the anticyclone close to the southern tip of Greenland. Thus the mesoscale simulations as well as the ECMWF analyses reveal an extended mixing region of moist subtropical and dry Arctic air on the edge of the anticyclone. Keeping the quasi-persistence of the Greenland high in mind [Scorer, 1988] this region could be a preferred location for stratosphere-troposphere exchange by quasihorizontal mixing in an anticyclonically dominated flow regime. The low humidity may result from cold temperatures recently encountered by the air parcels (see Figure 8c) because if air cools below the saturation temperature, water vapor is lost due to condensation and sedimentation of ice particles. During a later warming, the water vapor mixing ratio remains unchanged and therefore reflects essentially the previously encountered low temperature, analogue to the freeze-drying at the tropical tropopause.

\subsubsection{Deep Tropopause Fold, 15 May 2002}

[24] The last two legs of the westbound ferry from Goose Bay to Montreal and continuing to Oklahoma on 15 May 2002, 0540-0650 and 0840-1105 UTC crossed an intensifying cyclone centered over Montreal (Figure 9 and compare to Figure 1). The flight legs intercepted the left hand exit region (thick blue line in Figure 9) and the entrance region (thick red line in Figure 9) of the curved jet stream. Along the flight tracks the dynamical tropopause decreases from $10 \mathrm{~km}$ to $6.5 \mathrm{~km}$ and wells up to $12 \mathrm{~km}$ toward the anticyclone above the mid west of the United States (compare to Figure 1). The substantial $2 \mathrm{~km}$ tropopause drop near $80^{\circ} \mathrm{W}$ in Figure 1 indicates the existence of a tropopause fold associated with the jet stream. Although there is only a weak indication of a tropopause fold near the jet exit region along the blue flight leg, MM5 simulations of this event reveal a deeper fold to the south. The water vapor concentration is low down to about $8 \mathrm{~km}$ altitude (Figure 9). The sharp vertical gradient at this altitude marks the location of the tropopause at the exit region. Below the tropopause, ascending motions associated with the warm sector of the frontal system squeeze a fold-like structure vertically and sustain the large vertical gradient in the water vapor mixing ratio (simulated vertical winds reach $+6 \mathrm{~cm} \mathrm{~s}^{-1}$; not shown). The thin strongly backscattering layer due to clouds at this location supports this finding (see Figure 1).

[25] Within the jet stream region the observed water vapor distribution exhibits a complex structure. On the cyclonic shear side, dry stratospheric air intrudes down to about $2 \mathrm{~km}$ altitude in a main tropopause fold with a length of about $800 \mathrm{~km}$ (Figure 9). At the lower tip, fine-scale dry air even penetrates down to the ground. The width of the 
(a)

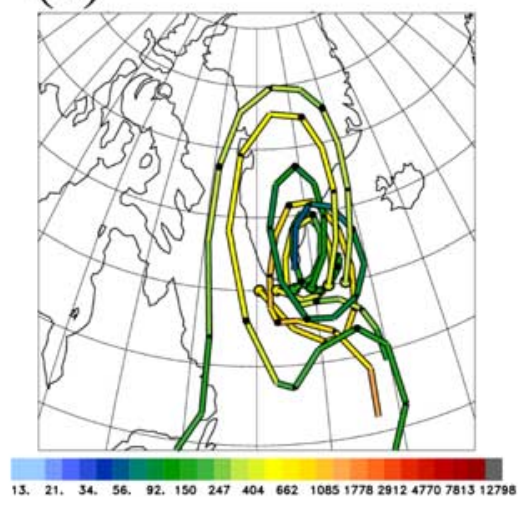

(b)

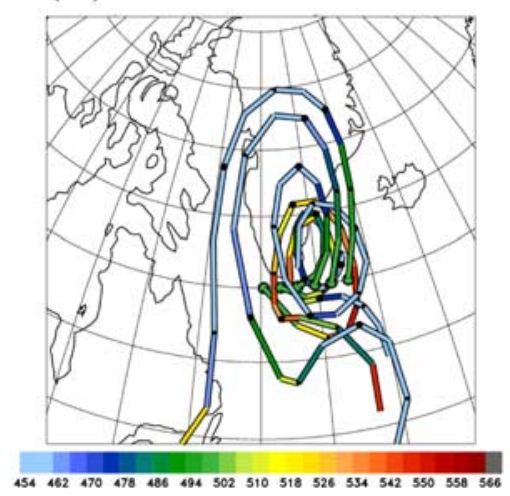

(c)

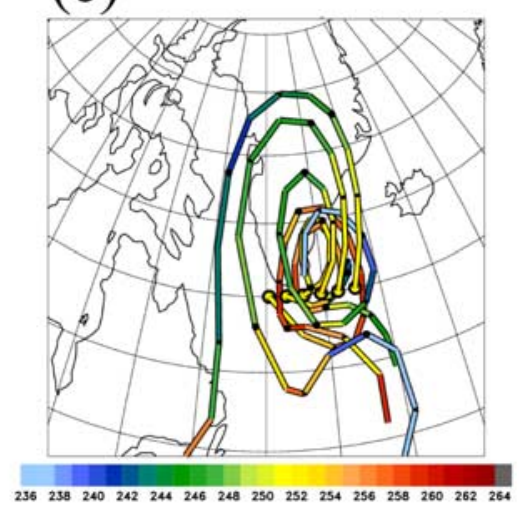

Figure 8. ECMWF backward trajectories arriving at $500 \mathrm{hPa}$ along the DLR Falcon flight track on 14 May 2002, 0000 UTC. (a) Water vapor mixing ratio $\left(\mathrm{mg} \mathrm{kg}^{-1}\right)$, (b) pressure (hPa), and (c) temperature $(\mathrm{K})$. Every full day is marked by a big black dot, and every half day is marked by a small black dot.

fold at $8 \mathrm{~km}$ altitude is about $300 \mathrm{~km}$. The minimum mixing ratio measured inside the main fold amounts to $\mathrm{q} \approx 0.04 \mathrm{~g} \mathrm{~kg}^{-1}$ extending down to $4 \mathrm{~km}$ altitude and increases to about $\mathrm{q} \approx 0.1 \mathrm{~g} \mathrm{~kg}^{-1}$ at $2 \mathrm{~km}$ altitude. Southwest of the entrance region of the jet stream, weaker multiple folds appear as finger-like oscillations in the water vapor field with about $2 \mathrm{~km}$ amplitude, each associated with a local wind maximum within the largescale jet. Although these dry intrusions do not extend vertically as deep as the main fold, they cover a significant portion of the middle and upper troposphere in the entrance region of the jet stream. The water vapor mixing ratio in this region is less than $0.5 \mathrm{~g} \mathrm{~kg}^{-1}$ but never falls below $0.1 \mathrm{~g} \mathrm{~kg}^{-1}$.

[26] The aerosol distribution in the region of the tropopause fold is dominated by weakly backscattering $\left(\mathrm{R}_{1064 \mathrm{mn}} \approx 2-4\right)$ filaments. Similar to the narrow filament case on 13 May 2002 these aerosol filaments are included as a whole in the downward motion in the tropopause fold, actually low backscatter values penetrate wedge-like down to the ground. In Figure 9, the $0.3 \mathrm{~g} \mathrm{~kg}^{-1}$ (480 ppmv) water vapor mixing ratio contour marks an approximate boundary between tropospheric and former UT/LS air masses. Evidently, the filaments follow the main intrusion directly whereas elevated values of $R_{1064}$ within the multiple fold region (outside the main fold) may arise from previous intrusions (generated preferentially with the Rocky mountain trough) which have already been eroded. Near $44^{\circ} \mathrm{N}$, at $5-8 \mathrm{~km}$ altitude the filaments extend even to very dry air masses with $\mathrm{q} \approx 0.02 \mathrm{~g} \mathrm{~kg}^{-1}(\approx 30 \mathrm{ppmv})$ which confirms that they originate in the lower stratosphere.

[27] The simulated water vapor field agrees well with the observed structures, even for the small amplitude oscillations of the dry fingers in the transition zone from high to low q values (Figure 9) at the anticyclonic shear side of the jet stream. As in the narrow filament case, however, the numerical model simulations predict twice as large water vapor mixing ratios inside the tropopause fold and near the tropopause: most likely an effect of the lower spatial resolution of the mesoscale model compared to the DIAL data. The simulated vertical wind in the tropopause fold reaches values of $-6 \mathrm{~cm} \mathrm{~s}^{-1}$ directly beneath the core of the jet stream. Furthermore, the model indicates several patches of cut-off low water vapor concentration near $2 \mathrm{~km}$ altitude. These patches are separated from the main intrusion and will later be mixed with lower tropospheric air. Although we have not calculated ECMWF backward trajectories for this particular case, the observations and the mesoscale model simulations clearly indicate irreversible injection and mixing of dry stratospheric air masses into the lower troposphere.

\subsubsection{Streamer, 17 June 2002}

[28] Pronounced gradients of middle to upper tropospheric water vapor mixing ratio also occurred on the first two eastbound flights in mid-June 2002 (Figure 2). Similar to the event described in the former section a tropopause fold was measured near $85^{\circ} \mathrm{W}$ on 16 June 2002 and again, weakly backscattering aerosol filaments exist in and near the tropopause fold. On the way to the Azores the DIAL observed strong zonal water vapor gradients, e.g., near $40^{\circ} \mathrm{W}$ on 17 June 2002 (Figure 2). These gradients are obviously related to the differential advection of moist subtropical and dry polar air masses, (compare to Figure 3b). An interesting structure occurs on the third flight leg west of $20^{\circ} \mathrm{W}$ on 17 June 2002 between 1800 and 1900 UTC: a horizontal $300 \mathrm{~km}$ long dry layer between 4 and $6 \mathrm{~km}$ altitude that opens out into a tropopause fold at about $19^{\circ} \mathrm{W}$. Figures 1 and $3 \mathrm{~b}$ reveal that the DLR Falcon crossed the southernmost tip of a streamer between the Azores and northwest Spain. In the tropopause maps, the evolution of the streamer is represented by the south-eastward transport of potentially colder air and the associated undulation of the jet stream near $20^{\circ} \mathrm{W}$ (Figure 3b).

[29] Between 1200 UTC and 1800 UTC the streamer moves from west to east along the flight track at midtropospheric levels $(5-6.5 \mathrm{~km})$, see Figure 10. ECMWF analyses show ascending motion on the front side and descending flow on the rear side of the streamer. Whereas the ascending moist air increases the water vapor gradient in the vicinity of the streamer, the descending motion on the rear side results in a more diffusive structure. In contrast to the previous cases where the intrusions, which actually are complex downward spiraling dry 2D air mass sheets, were cut nearly perpendicularly, the profiling plane here cuts the tip of the 


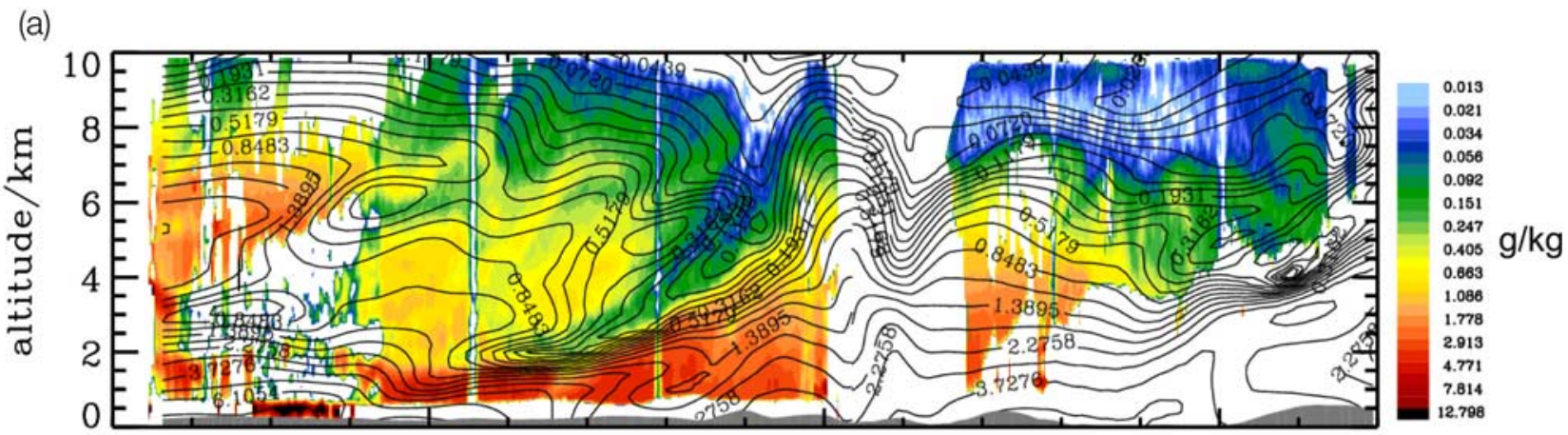

(b)

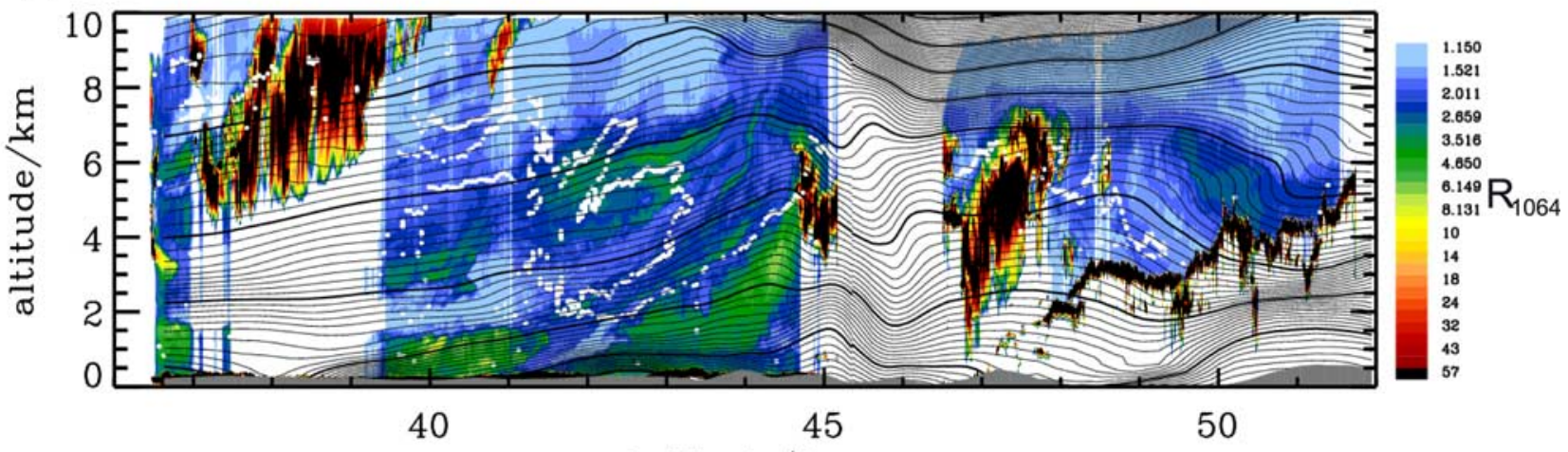

latitude/deg

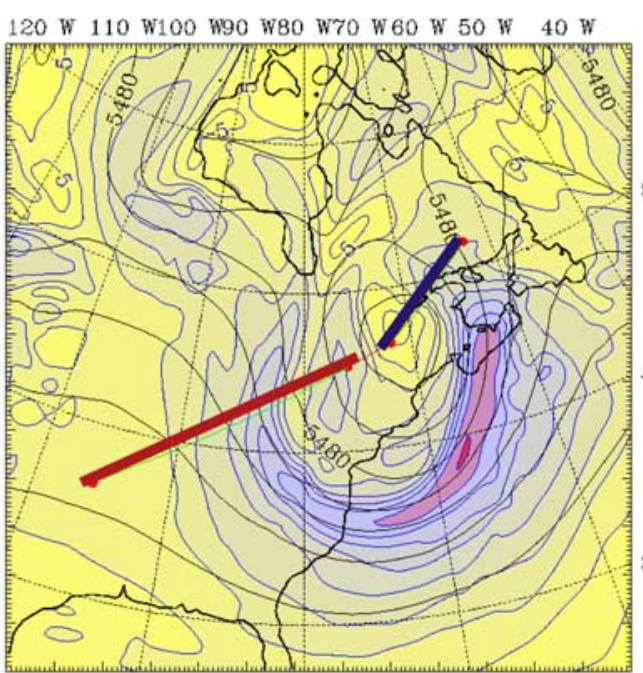

(c)

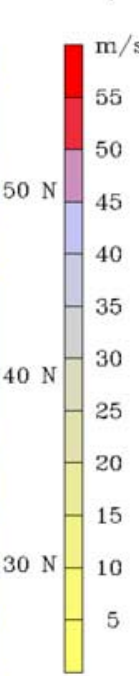

120 W 110 W100 W90 W80 W70 W60 W 50 W 40 W

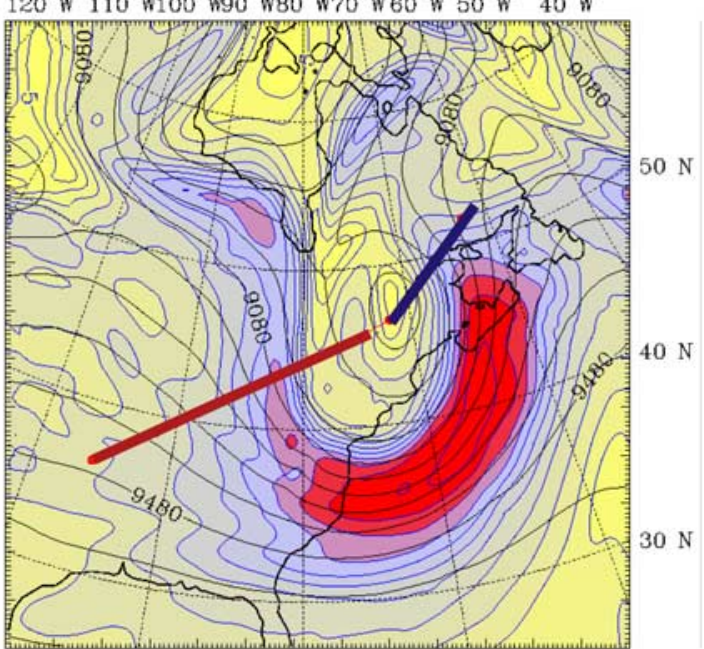

(d)

Figure 9. (a) DIAL water vapor mixing ratio $\left(\mathrm{g} \mathrm{kg}^{-1}\right.$, color coded) on 15 May 2002, 0540-0650 UTC (blue segment) and from 0840 to 1105 UTC (red segment). Superimposed simulated water vapor mixing ratio $\left(\mathrm{g} \mathrm{kg}^{-1}\right.$, black contour lines) is valid at $0800 \mathrm{UTC}(+20$ hours) for the red segment and at 0600 UT (+18 hours) for the blue segment. (b) Aerosol backscatter (color coded) and simulated potential temperature $(\mathrm{K}$, thin black solid lines every $2 \mathrm{~K}$, thick lines every $10 \mathrm{~K})$ valid at the same times as in Figure 9a; the white dots mark locations where the DIAL measured a water vapor mixing ratio of $0.3 \mathrm{~g} \mathrm{~kg}^{-1}$. (c, d) Geopotential height (m, black lines) and horizontal wind speed ( $\mathrm{m} \mathrm{s}^{-1}$, color shaded and blue contour lines) at 500 (Figure 9c) and 300 (Figure 9d) hPa.

dry streamer more lengthwise, resulting in the comparatively large extension. This geometry reflects the fact that typically, the tip of an intrusion experiences intense shearinduced contour stretching and thus strongly lags the large-scale baroclinic folding movement until it finally is cut off (repeatedly). The location of the dry layer, the humid region above and the onset of increasing water vapor near $14^{\circ} \mathrm{W}$ are precisely reproduced by the ECMWF analyses, however, the water vapor mixing ratios observed by the DIAL, i.e., $\mathrm{q} \approx 0.02-0.05 \mathrm{~g} \mathrm{~kg}^{-1}$ $(30-80 \mathrm{ppmv})$ in the streamer and minima even below $0.02 \mathrm{~g} \mathrm{~kg}^{-1}(\approx 30 \mathrm{ppmv})$ in the driest layer, are again 
(a)

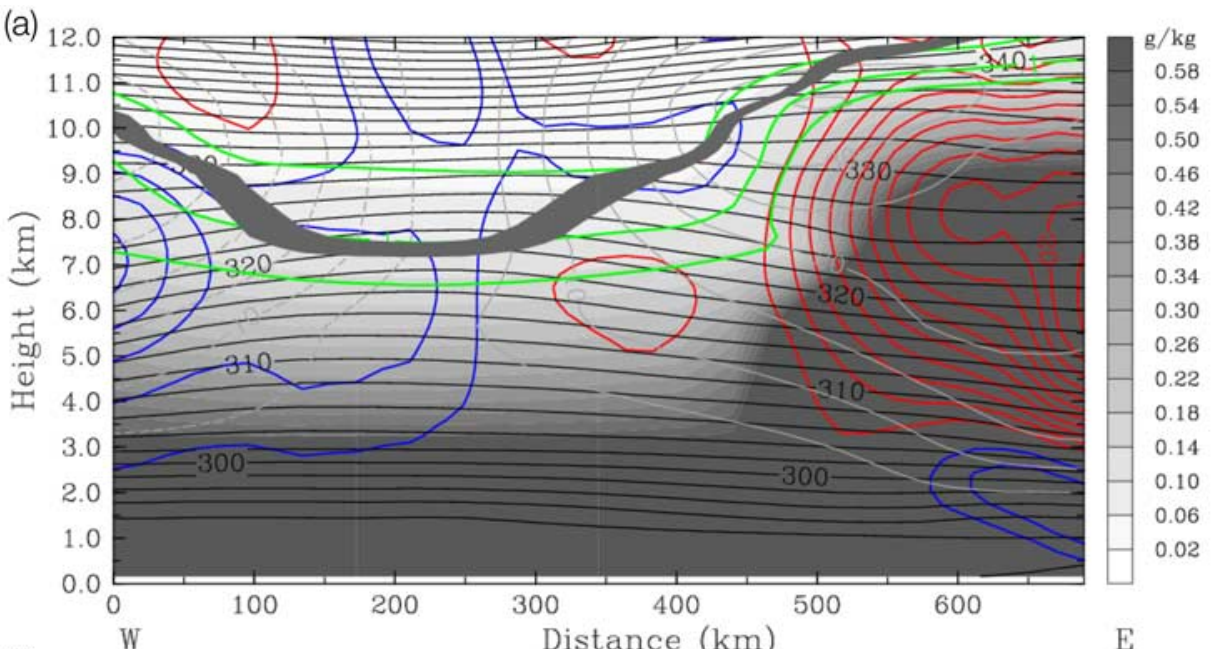

(b)

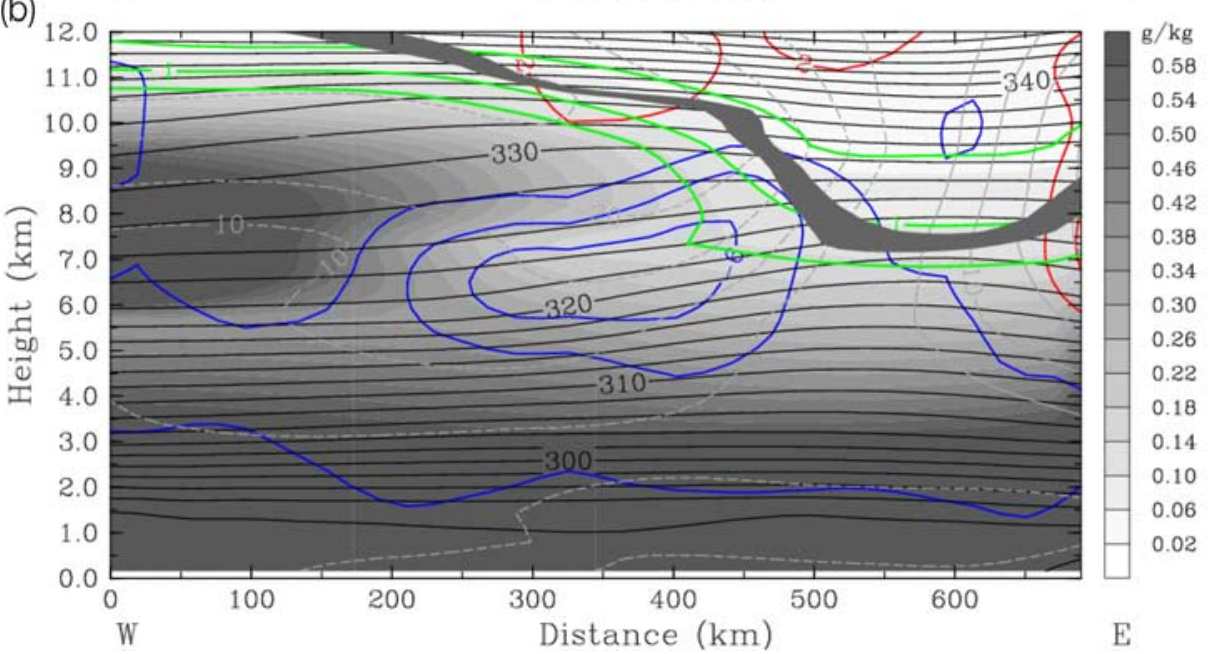

Figure 10. Vertical sections of water vapor mixing ratio $\left(\mathrm{g} \mathrm{kg}^{-1}\right.$, color shaded and green contours at $0.05,0.10$, and $\left.0.15 \mathrm{~g} \mathrm{~kg}^{-1}\right)$, potential temperature ( $\mathrm{K}$, black solid lines), section-normal wind speed $\left(\mathrm{m} \mathrm{s}^{-1}\right.$; gray solid lines, wind into the plane; gray dashed lines, wind out of the plane), and PV ribbon 2-2.5 PVU, indicating the dynamical tropopause along the third leg of the eastbound ferry flights on 17 June 2002, (a) 1200 and (b) 1800 UTC.

significantly lower than the ECMWF values. In Figures 7 and 10 the green lines mark simulated water vapor mixing ratios of $\mathrm{q}=0.05(80), 0.10(160)$, and $0.15(240) \mathrm{g} \mathrm{kg}^{-1}$ (ppmv), respectively. According to Ovarlez et al. [1999], the water vapor mixing ratio at the dynamical tropopause has a large spread: it varies between 10 and $80 \mathrm{~g} \mathrm{~kg}^{-1}$ $(\approx 20-120 \mathrm{ppmv})$ for a value of $2 \mathrm{PVU}$; for $3.5 \mathrm{PVU}$ the spread is reduced to about 10 to $0.05 \mathrm{~g} \mathrm{~kg}^{-1}(\approx 20-$ 80 ppmv). The three cases (Greenland anticyclone, deep tropopause fold, and streamer) show that values $\mathrm{q} \approx$ $0.05 \mathrm{~g} \mathrm{~kg}^{-1}(80 \mathrm{ppmv})$ are situated close to or above the dynamical 2 PVU tropopause, while values $\mathrm{q} \approx 0.10 \mathrm{~g} \mathrm{~kg}^{-1}$ (160 ppmv) can be either stratospheric or tropospheric.

[30] At the lower tip of the streamer an overturning structure with enhanced aerosol backscatter ratio $\mathrm{R}_{1064} \approx$ 2-4 is observed where the ECMWF 2 PVU tropopause dips down to minimum altitude (Figure 2). It indicates strong wind shear, presumably associated with the cross-jet circulation. A few percent depolarization at $532 \mathrm{~nm}$ and a small color ratio $\mathrm{CR}_{532 / 1064} \approx 1.7 \pm 0.3$ are comparable to the other particle observations inside intrusions. On both sides of the streamer, cirrus clouds are observed while the streamer itself is cloud free (confirmed by IR and VIS NOAA AVHRR imagery at 1423 UTC; http://www.sat.dundee.ac.uk). At the lowest $2 \mathrm{~km}$, the maritime boundary layer is evident with enhanced backscatter ratios and an entrainment/mixing layer of about $1 \mathrm{~km}$ depth near its top (note also the weak stratification in the simulations in Figure 10). A color ratio near 1 (not shown) is most likely due to the presence of large sea salt particles.

[31] The possibility to reduce humidity background errors in NWP models by utilizing the correlation between humidity and PV fields is presently investigated by NWP centers [e.g., Hólm et al., 2002]. Owing to the limited coverage of operationally available water vapor observations, a coupling of humidity and vertical motion during the assimilation may add valuable information, contained in the $\mathrm{H}_{2} \mathrm{O}-\mathrm{PV}$ anticorrelation at UT/LS levels, however it is crucial, by how much the benefit on the NWP initialization is degraded by deviations in details, strength, positioning and temporal development of the anomalies. The vertical extent of the exchange regions varies considerably. The 
Backscatter Coeff at 1064nm on 13. May 02

Lat: 61.404 Lon: -13.701

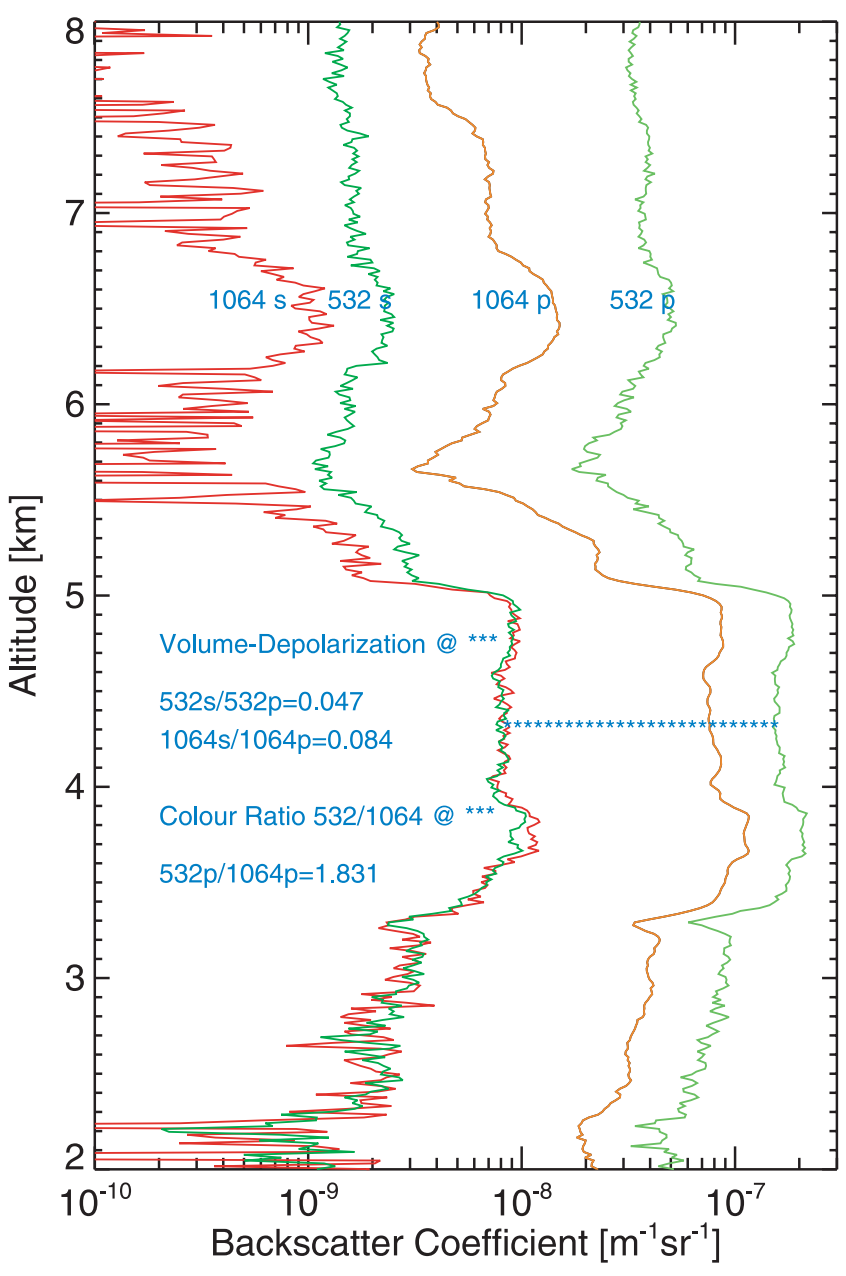

Figure 11. Profiles of parallel- and cross-polarized backscatter coefficients at 532 and $1064 \mathrm{~nm}$ on 13 May 2002, 2202 UTC. Position $\left(13.7^{\circ} \mathrm{W}\right)$ is marked in Figure 4. Given depolarization and color ratios are valid for the aerosol filaments, inside the intrusion, between 3.2 and $5 \mathrm{~km}$ altitude.

deep tropopause fold over Canada and the narrow filament over the Norwegian Sea range from $8 \mathrm{~km}$ altitude down to below 2 to $3 \mathrm{~km}$, while the dry regions of the streamer and the Greenland anticyclone only span the altitude range from 5 to $6 \mathrm{~km}$ and 5 to $8 \mathrm{~km}$, respectively. The geographical distribution of our observations corresponds to the ECMWF tropopause fold climatology by Sprenger et al. [2003], where medium and deep stratospheric intrusions most frequently appear north of $40^{\circ} \mathrm{N}$.

\subsection{Particle Observations}

[32] The particle distributions along the Atlantic storm track (Figures 1 and 2) show three features: clouds, aerosol filaments and "optically clean" background atmosphere, distinguishable by the backscatter ratio. The typical zonal scale of synoptic systems (a few thousand kilometers) reflects in the intermittent occurrence of cirrus clouds associated with fronts, e.g., $\sim 92^{\circ} \mathrm{W}, \sim 72^{\circ} \mathrm{W}, \sim 52^{\circ} \mathrm{W}$ and east of $20^{\circ} \mathrm{W}$ on the westbound and $\sim 50^{\circ} \mathrm{W}, \sim 35^{\circ} \mathrm{W}$, $\sim 21^{\circ} \mathrm{W}$ and $\sim 14^{\circ} \mathrm{W}$ on the eastbound ferry flight. In between, large areas $(\sim 60 \%)$ exhibit tropospheric background conditions $\left(\mathrm{R}_{1064 \mathrm{~nm}}<2\right)$, while extended coherent aerosol structures (filaments) with $\mathrm{R}_{1064}>2$ occur in and around intrusions of UT/LS air into the middle and lower troposphere. The optically thin "background" (BG) particles $\left(\mathrm{R}_{1064 \mathrm{~nm}} \approx 1-1.5\right)$, interspersing the troposphere are aspherical $\left(\delta_{\mathrm{p}} \approx\right.$ few $\left.\%\right)$ and much smaller than $1 \mu \mathrm{m}$ $\left(\mathrm{CR}_{532 / 1064} \approx 4-6\right)$. Possible sources/sinks, sizes, composition, effects and the ubiquity of tropospheric aerosol is subject of a bulk of literature, some of relevance for this study are, e.g., Murphy et al. [1998], Newell et al. [1999], Raes et al. [2000], and Minikin et al. [2003]. We will focus to the filaments with elevated backscatter ratios $\left(\mathrm{R}_{1064 \mathrm{~nm}} \approx 2-4\right)$ inside and in the vicinity of dry intrusions. Representative profiles of $\beta_{532(\|, \perp)}$ and $\beta_{1064(\|, \perp)}$ and derived quantities across the intrusion (3.2-5 km altitude) from 13 May (Figure 11) show that these particles exhibit higher depolarization $\left(\delta_{\mathrm{p}, 1064} \approx 11 \pm 3 \%\right)$ and smaller color ratios $\left(\mathrm{CR}_{532 / 1064} \approx 1.8 \pm 0.2\right)$ than the $\mathrm{BG}$ particles, indicating solid phase and roughly micron radius. Owing to their small optical depth, their lidar ratio is uncertain and ranges between 40 and 80 . The color and the depolarization ratio vary negligibly along the filaments, both inside and outside the intrusions, suggesting uniform microphysical properties. Inside the intrusions, the particles exhibit a tilting layered structure, a signature of stable stratification and little vertical mixing (no turbulence). The tilt roughly follows the axes of the low water vapor intrusions, indicating that the downward transport leaves the (initially quasi-horizontal) internal structure of the air mass mostly unaltered. The layers partially extend beyond the dry domains. Similar aerosol patterns occur in stratospheric intrusions reported by Hoinka et al. [2003].

[33] As no in situ particle measurements were performed during the flights, insight into origin and composition of filaments associated with UT/LS intrusions is extracted from their optical properties, their internal structure, back trajectories and analogies to previous (combined) remote and in situ measurements. The uniformity of the optical properties, i.e., backscatter, color, and depolarization ratio, all over the filaments suggests the absence of particle transformations, i.e., the particles are transported passively. About $11 \%$ particle depolarization indicates aspherical particles and (due to the polymorphic microscopic structure of various tropospheric particles) large uncertainty in the particles' sizes. This and the color ratio $\mathrm{CR}_{532 / 1064} \approx 1.8$ indicate a maximum of the particle size distribution (PSD) roughly at effective radii of $0.5 \mu \mathrm{m}<\mathrm{r}_{\mathrm{p} \text {,eff }}<1.5 \mu \mathrm{m}$, although an additional mode of Aitken particles $0.1 \mu \mathrm{m}$ with low scattering efficiency at lidar wavelengths cannot be excluded. Regarding the uniformity of depolarization and color ratio, the filaments are most likely composed of an aged aerosol with a (spectrally) broad PSD.

[34] The generation of the horizontal filaments and their tilting bulk transport to lower levels are independent processes, otherwise they would not maintain such laminar appearance and quasi-parallel organization. Formation of layers in the troposphere and lower stratosphere may be associated with gravity waves [e.g., Reid, 1982; Danielsen et al., 1991], lateral spreading-out of convective air in the upper troposphere [e.g., Newell et al., 1999] or conversion 
of horizontal to vertical gradients by vertical shear aligned with horizontal gradients [Appenzeller and Holton, 1997]. Repeated layering followed by large-scale differential vertical motion, which is often a quasi-horizontal layertype process, gradually generates multiple stacked layers, which indeed are frequently observed. The undisturbed appearance of the layers inside the intrusions evinces that no mixing has occurred yet and reflects the nonturbulent character of the intrusion process. Further indication that mixing across the intrusions' boundaries is very slow is supplied by the large water vapor and backscatter ratio gradients. As the spatial resolution of the $\mathrm{q}$ fields is $\sim 10$ times lower than that of the $\mathrm{R}_{1064}$ measurements, the particle filaments partly seem to cross the boundary of the q filament, which however must be a smoothing artifact rather than a hint to selective mixing.

[35] Particle filaments, embedded in air with $\mathrm{q}<$ $0.2 \mathrm{~g} \mathrm{~kg}^{-1}$, come from the UT/LS region, which is corroborated by ECMWF trajectories (e.g., in Figure 6). Mostly, the filaments stay within the $\mathrm{q} \approx 0.2 \mathrm{~g} \mathrm{~kg}^{-1}$ contour as inside the isolated young intrusion on 13 May 2002, where the $\mathrm{R}_{1064}=2$ contour (filament boundary) and the $\mathrm{q}=0.2 \mathrm{~g} \mathrm{~kg}^{-1}$ contour (intrusion boundary) closely match all along the intrusion from $15^{\circ} \mathrm{W}$ to $13^{\circ} \mathrm{W}$. Except for these particle filaments, $\mathrm{R}_{1064}$ inside the intrusion is below 2. Sharply bounded patches of particles outside the intrusions likely mark small segregations detached from the intrusion (smoothed out in $\mathrm{H}_{2} \mathrm{O}$ ), implying a more complex water vapor field on smaller scales than shown in Figures 1 and 2. On 15 May, coherent aerosol filaments seem to extend across the $0.3 \mathrm{~g} \mathrm{~kg}^{-1}$ contour at the intrusion boundary (Figure 9), but it seems likely that this again is a resolution artifact as stirring and fragmentation of multiple intrusions in presence of ongoing cyclogenesis continuously reduces the scales below the $\mathrm{H}_{2} \mathrm{O}$ data resolution. The observations suggest that mixing of intruded air to the troposphere initially is dominated by intense stirring of filaments to ever smaller scales, rather than by turbulent diffusion, which is too slow and takes over only after the scales have reduced sufficiently (compare to section 3.2.1). A tendency toward larger water vapor and aerosol gradients at the lower boundary of the intrusions presumably results from the larger shear at the intrusions bases. Against this, there is no indication of vertical changes in CR and $\delta$ across the intrusion, but rather a sporadic distribution of more or less dense filaments.

[36] According to the water vapor mixing ratio, the particle filaments clearly were transported down from the UT/LS region, but what are their origin and their composition? The only relevant particles in the LS, sulfuric acid from volcanic eruptions [Jäger, 1992], can be ruled out because they are spherical and much too small $(\sim 0.1 \mu \mathrm{m})$. The diversity of UT aerosols is much larger: Ice, i.e., cirrus, can be excluded because it would reflect the intense adiabatic processes and has never been observed as such multiple layers. Directly emitted (primary) aircraft exhaust, the main particle source in the UT/LS between 9 and $12 \mathrm{~km}$ [Schumann et al., 1996] is much too small as well [Petzold et al., 1999], and would, if at all, again nucleate ice particles [Kärcher and Solomon, 1999]. Meteoritic "smoke" particles constitute only a negligible (and small- size) aerosol component in the troposphere [Murphy et al., 1998]. Sulfate aerosols, partially ammoniated aqueous sulfuric acid particles, are hygroscopic, but (also due to their large deliquescence-efflorescence hysteresis) may indeed remain solid in the presence of very low RH inside intrusions [Colberg et al., 2002]. However, they should undergo phase changes outside the folds. Finally, the only residing particle fractions coming into question are organic/ biogenic or crustal/soil particles, which may reach the UT/LS by an interaction of storms, deep convection, synoptic-scale upwelling and up-sliding motion in a warm conveyor belt. The primary source regions of crustal particles are deserts [e.g., Prospero et al., 2002] of which the Sahara is the only one to be considered for the northern Atlantic region. However, the optical properties, reported for Saharan dust differ considerably from our observations: $\mathrm{A} \mathrm{CR}_{532 / 1064} \approx 0.7-1.4$ and $\delta_{\mathrm{p}, 532} \approx 15-$ $25 \%$ as found by Ansmann et al. [2003] in a Saharan dust plume are typical values over Europe [Jäger et al., 1988; Mattis et al., 2002]. During long-range transport, desert dust particles of nearly micron size occur mostly at altitudes between 2 and $5 \mathrm{~km}$ and rarely reach up to $8 \mathrm{~km}$. Moreover, Saharan dust is mainly exported to the Southern North Atlantic or even further south and does hardly reach that far north - actually no dust outbreak event has been reported for the period of our observations. Therefore the particles most likely originate in forest fire plumes, e.g., over Siberia, as indicated by the back trajectories on 14 May 00UT and TERRA/MODIS observations of various long-lasting fire sources in that region (e.g., http://rapidfire.sci.gsfc.nasa.gov/gallery). There is robust evidence, that fire smoke particles can both reach stratospheric levels [Fromm and Servranckx, 2003] and be transported on a continental scale [Forster et al., 2001]. For example, a particle depolarization of $6-11 \%$ [Fiebig et $a l ., 2002$ ] and effective radii $\mathrm{r}_{\mathrm{p}, \mathrm{eff}} \approx 0.25 \mu \mathrm{m}$ [Wandinger et al., 2002] were found in a forest fire plume, transported from Canada to Europe in Summer 1998. Jost et al. [2004] observed transport of forest fire tracers deep into the stratosphere over Canada in early July 2002, about one month after our measurements.

\section{Conclusions}

[37] Tropospheric water vapor and aerosol/cloud distributions, observed with an airborne DIAL in mid-May and mid-June 2002 across the northern and middle Atlantic Ocean have been presented. During 8 flights from Germany to Oklahoma (US) via Iceland, Greenland, Goose Bay and back via Maine and the Azores, very inhomogeneous water vapor and particle distributions are observed with large vertical and horizontal gradients, most of which are associated with active weather systems as rapidly developing cyclones. Typically, when cyclones are propagating along the storm track, tropopause folds associated either with the subtropical or the polar jet stream occur.

[38] In most instances, water vapor and analyzed/simulated PV fields are anticorrelated except at small scales. Deep intrusions of stratospheric air into the (lower) troposphere occur on the cyclonic side of the jets, occasionally also as multiple folds within its entrance region. The quasieastward movement of cyclones and streamers enhances 
water vapor gradients on the front side of the systems due to the predominant ascending motions. On the rear side, however, the dried midtropospheric air shows various structures as finger-like dry intrusions or extended dry horizontal layers associated with a propagating streamer. In these cases, calculated PV fields do not reflect the water vapor distribution. Inside the tropopause folds, multiply stacked filaments of enhanced particle backscatter are observed, following the axes of the intrusions. These solid, roughly micron-sized particles most likely originate in forest fires (e.g., over Siberia), from where they are injected to the UT/LS by deep convection and later on reenter the troposphere in actively developing cyclones. Laminar appearance of the stacked particle layers/filaments and large $\mathrm{H}_{2} \mathrm{O}$ /backscatter gradients at the edges of folds suggest that these intrusions have not yet been mixed, but are eroded on timescales of several days by stretching, stirring and final turbulent diffusion when their scales have been sufficiently reduced.

[39] Enhanced gradients may also be related to weaker dynamical structures as the presence of a large-scale dry intrusion into the troposphere on the edge of the quasistationary high-pressure system over Greenland. Due to the long-lasting advection of moist, subtropical air masses and their mixing with dry, polar air masses this region might be a favorite place for stratosphere-troposphere exchange by quasi-horizontal (isentropic) transport on long timescales. As with small-scale multiple intrusions, this would imply errors in the initialization of NWP models if, as is presently investigated by NWP centers, the $\mathrm{H}_{2} \mathrm{O}-\mathrm{PV}$ anticorrelation at upper tropospheric/lower stratospheric levels would be utilized to couple humidity and vertical motion in order to reduce model background errors.

[40] Meteorological analyses and backward trajectories (ECMWF) as well as MM5 mesoscale simulations have been used to trace the dynamical origin of the observations. For a narrow filament (section 3.2.1), for a deep tropopause fold (section 3.2.3) and for a streamer (section 3.2.4) we have shown that the dry air originates from the stratospheric reservoir. The MM5 simulations suggest at least partial irreversible injection and mixing of dry stratospheric air masses into the lower troposphere. The origin of very dry air in a Greenland anticyclone (section 3.2.2) is not as clear, here additional investigations have to be done. The simulations reproduce the observed structures very well. However, inside the dry intrusions the MM5-simulated water vapor mixing ratios were more than twice that observed. This may simply result from the finite spatial resolution of the model.

[41] Acknowledgments. We acknowledge the ECMWF for the highquality synoptic data and thank the reviewers for their valuable comments. This work was funded by the ESA under the contract number 16180/02/NL/ FF and the United States National Science Foundation (NSF). The MM5 computations were performed at the German High Performance Computing Center for Climate and Earth System Research in Hamburg, Germany.

\section{References}

Ackermann, J. (1998), The extinction to backscatter ratio of tropospheric aerosol: A numerical study, J. Atmos. Oceanic Technol., 15, 1043-1050.

Ancellet, G., M. Beekmann, and A. Papayannis (1994), Impact of a cut-off low development on downward transport of ozone into the troposphere, J. Geophys. Res., 99, 3451-3468.

Ansmann, A., et al. (2003), Long-range transport of Saharan dust to northern Europe: The 11-16 October 2001 outbreak observed with EARLINET, J. Geophys. Res., 108(D24), 4783, doi:10.1029/ 2003JD003757.
Appenzeller, C., and H. C. Davies (1992), Structure of stratospheric intrusions into the troposphere, Nature, 358, 570-572.

Appenzeller, C., and J. R. Holton (1997), Tracer lamination in the stratosphere: A global climatology, J. Geophys. Res., 102, 13,555-13,569.

Appenzeller, C., H. C. Davies, and W. A. Norton (1996a), Fragmentation of stratospheric intrusions, J. Geophys. Res., 101, 1435-1456.

Appenzeller, C., J. R. Holton, and K. H. Rosenlof (1996b), Seasonal variation of mass transport across the tropopause, J. Geophys. Res., 101, $15,071-15,078$.

Browell, E. V., E. F. Danielsen, S. Ismail, G. L. Gregory, and S. M. Beck (1987), Tropopause fold structure determined from airborne lidar and in situ measurements, J. Geophys. Res., 92, 2112-2120.

Browell, E., S. Ismail, and W. B. Grant (1998), Differential absorption lidar (DIAL) measurements from air and space, Appl. Phys. B, 67, 399-410.

Chahine, M. T. (1992), The hydrological cycle and its influence on climate, Nature, 359, 373-380.

Colberg, C. A., B. P. Luo, H. Wernli, T. Koop, and T. Peter (2002), A novel model to predict the physical state of atmospheric $\mathrm{H}_{2} \mathrm{SO}_{4} / \mathrm{NH}_{3} / \mathrm{H}_{2} \mathrm{O}$ aerosol particles, Atmos. Chem. Phys. Discuss., 2, 2449-2487.

Danielsen, E. F. (1968), Stratospheric-tropospheric exchange based on radioactivity, ozone and potential vorticity, J. Atmos. Sci., 25, 502-518.

Danielsen, E. F., et al. (1991), Irreversible transport in the stratosphere by internal waves of short vertical wavelength, J. Geophys. Res., 96, $17,433-17,452$

Dudhia, J. (1993), A non-hydrostatic version of the Penn State-NCAR mesoscale model: Validation tests and simulation of an Atlantic cyclone and cold front, Mon. Weather Rev., 121, 1493-1513.

Dudhia, J., D. Gill, Y.-R. Guo, K. Manning, and W. Wang (2001), PSU/ NCAR mesoscale modeling system tutorial class notes and user's guide: MM5 modeling system version 3, 300 pp., Penn. State Univ./Natl. Cent. for Atmos. Res., Boulder, Colo.

Ehret, G., K. P. Hoinka, J. Stein, A. Fix, C. Kiemle, and G. Poberaj (1999), Low-stratospheric water vapor measured by an airborne DIAL, J. Geophys. Res., 104, 31,351-31,359.

Eisele, H., H. E. Scheel, R. Sladkovic, and T. Trickl (1999), High-resolution lidar measurements of stratosphere-troposphere exchange, J. Atmos. Sci., $56,319-330$.

Elbern, H., J. Kowol, R. Sladkowich, and H. Ebel (1997), Deep stratospheric intrusions: A statistical assessment with model guided analyses, Atmos. Environ., 31, 3207-3226.

Elliott, W. P., and D. J. Gaffen (1991), On the utility of radiosonde humidity archives for climate studies, Bull. Am. Meteorol. Soc., 72, 1507-1520.

Fabian, P., and P. G. Pruchniewicz (1977), Meridional distribution of ozone in the troposphere and its seasonal variations, J. Geophys. Res., 82, 2063-2073.

Fiebig, M., A. Petzold, U. Wandinger, M. Wendisch, C. Kiemle, A. Stifter, M. Ebert, T. Rother, and U. Leiterer (2002), Optical closure for an aerosol column: Method, accuracy, and inferable properties applied to a biomassburning aerosol and its radiative forcing, J. Geophys. Res., 107(D21), 8130, doi:10.1029/2000JD000192.

Forster, C., et al. (2001), Transport of boreal forest fire emissions from Canada to Europe, J. Geophys. Res., 106, 22,887-22,906.

Fromm, M. D., and R. Servranckx (2003), Transport of forest fire smoke above the tropopause by supercell convection, Geophys. Res. Lett., 30(10), 1542, doi:10.1029/2002GL016820.

Gérard, E., D. G. H. Tan, L. Garand, V. Wulfmeyer, G. Ehret, and P. Di Girolamo (2004), Major advances foreseen in humidity profiling from the water vapor lidar experiment in space (WALES), Bull. Am. Meteorol. Soc., 85, 237-251.

Grell, G. A., J. Dudhia, and D. R. Stauffer (1994), A description of the fifth-generation Penn State/NCAR mesoscale model (MM5), NCAR Tech. Note, TN-398+STR, 117 pp., Natl. Cent. for Atmos. Res., Boulder, Colo.

Haynes, P. H., and J. Anglade (1997), The vertical scale cascade in atmospheric tracers due to large scale differential advection, J. Atmos. Sci., 54, $1121-1136$.

Hoinka, K. P., E. Richard, G. Poberaj, R. Busen, J.-L. Caccia, A. Fix, and H. Mannstein (2003), Analysis of a potential vorticity streamer crossing the Alps during MAP-IOP 15 on 6 November 1999, Q. J. R. Meteorol. Soc., 129, 609-632.

Hólm, E., E. Andersson, A. Beljaars, P. Lopez, J. F. Mahfouf, A. Simmons, and J.-N. Thépaut (2002), Assimilation and modelling of the hydrological cycle: ECMWF's status and plans, ECMWF Tech. Memo. 383, Eur. Cent. for Medium-Range Weather Forecasts, Reading, U. K.

Holton, J. R., P. E. Haynes, M. E. McIntire, A. R. Douglas, R. R. Rood, and L. Pfister (1995), Stratosphere-Troposphere Exchange, Rev. Geophys., 33, 403-439.

Hong, S.-Y., and H.-L. Pan (1996), Nonlocal boundary layer vertical diffusion in a medium-range forecast model, Mon. Weather Rev., 124, 2322-2339. 
Jäger, H. (1992), The Pinatubo eruption cloud observed by lidar at Garmisch Partenkirchen, Geophys. Res. Lett., 19, 191-194.

Jäger, H., W. Carnuth, and B. Georgii (1988), Observations of Saharan dust at a North Alpine mountain station, J. Aerosol Sci., 19, 1235-1238.

Jensen, E. J., and L. Pfister (2004), Transport and freeze-drying in the tropical tropopause layer, J. Geophys. Res., 109, D02207, doi:10.1029/ 2003JD004022.

Jost, H.-J., et al. (2004), In-situ observations of mid-latitude forest fire plumes in the stratosphere, Geophys. Res. Lett., 31, L11101, doi:10.1029/2003GL019253.

Kärcher, B., and W. Haag (2004), Factors controlling upper tropospheric relative humidity, Ann. Geophys., 22, 705-715.

Kärcher, B., and S. Solomon (1999), On the composition and optical extinction of particles in the tropopause region, J. Geophys. Res., 104, 27,441-27,459.

Kiehl, J. T., and K. E. Trenberth (1997), Earth's annual global mean energy budget, Bull. Am. Meteorol. Soc., 78, 197-208.

Koop, T., B. P. Luo, A. Tsias, and T. Peter (2000), Water activity as the determinant for homogeneous ice nucleation in aqueous solutions, Nature, 406, 611-614.

Kursinski, E. R., et al. (1996), Initial results of radio occultation observations of Earth's atmosphere using the Global Positioning System, Science, 271, 1107-1110.

Langford, A. O., C. D. Masters, M. H. Profitt, E.-Y. Hsie, and A. F. Tuck (1996), Ozone measurements in a tropopause fold associated with a cutoff low system, Geophys. Res. Lett., 23, 2501-2504.

Leiterer, U., H. Dier, and T. Naebert (1997), Improvements in radiosonde humidity profiles using RS80/RS90 radio sondes of Vaisala, Contrib. Atmos. Phys., 70, 319-336.

Manabe, S., and R. Weatherald (1967), Thermal equilibrium of the atmosphere with a given distribution of atmospheric humidity, J. Atmos. Sci. 24, $241-259$.

Marenco, A., et al. (1998), Measurement of ozone and water vapor by Airbus in-service aircraft: The MOZAIC airborne program, An overview, J. Geophys. Res., 103, 25,631-25,642.

Marseille, G. J., and F. Bouttier (2001), Climatologies of sensitive areas for short-term forecast error over Europe. A EUMETNET-EUCOS study, $E C M W F$ Tech. Memo. 334, Eur. Cent. for Medium-Range Weather Forecasts, Reading, U. K.

Mattis, I., A. Ansmann, D. Müller, U. Wandinger, and D. Althausen (2002), Dual-wavelength Raman lidar observations of the extinctionto-backscatter ratio of Saharan dust, Geophys. Res. Lett., 29(9), 1306, doi:10.1029/2002GL014721.

Minikin, A., et al. (2003), Aircraft observations of the upper tropospheric fine particle aerosol in the Northern and Southern Hemispheres at midlatitudes, Geophys. Res. Lett., 30(10), 1503, doi:10.1029/2002GL016458.

Mishchenko, M. I. (1991), Light scattering by randomly oriented axially symmetric particles, J. Opt. Soc. Am. A Opt. Image Sci., 8, 871-882.

Möller, F. (1963), On the influence of changes in the $\mathrm{CO}_{2}$ concentration in air on the climate, J. Geophys. Res., 68, 3877-3886.

Moreau, E., P. Lopez, P. Bauer, A. M. Tompkins, M. Janiskova, and F. Chevallier (2003), Variational retrieval of temperature and humidity profiles using rain rates versus microwave brightness temperatures, ECMWF Tech. Memo. 412, Eur. Cent. for Medium-Range Weather Forecasts, Reading, U. K.

Morgan, M. C., and J. W. Nielsen-Gammon (1998), Using tropopause maps to diagnose midlatitude weather systems, Mon. Weather Rev., 126, 2555 2579

Müller, H., and H. Quenzel (1985), Information content of multispectral lidar measurements with respect to the aerosol size distribution, Appl. Opt., 24(5), 648-654.

Murphy, D. M., D. S. Thomson, and M. J. Mahoney (1998), In situ measurements of organics, meteoritic material, mercury, and other elements in aerosols at 5 to 19 kilometers, Science, 282, 1664-1668.

Newell, R., V. Thouret, J. Y. N. Cho, P. Stoller, A. Marenco, and H. G. Smit (1999), Ubiquity of quasi-horizontal layers in the troposphere, Nature, 398, 316-319.

Ovarlez, J. P., F. J. van Velthoven, and H. Schlager (1999), Water vapor measurements from the troposphere to the lowermost stratosphere: Some signatures of troposphere to stratosphere exchanges, J. Geophys. Res., $104,16,973-16,978$

Petzold, A., A. Döpelheuer, C. A. Brock, and F. P. Schröder (1999), In situ observations and model calculations of black carbon emission by aircraft at cruise altitude, J. Geophys. Res., 104, 22,171-22,181.

Poberaj, G., A. Fix, A. Assion, M. Wirth, C. Kiemle, and G. Ehret (2002), All-solid-state airborne DIAL for water vapor measurements in the tropopause region: System description and assessment of accuracy, Appl. Phys. B, 75, 165-172.

Prospero, J. M., P. Ginoux, O. Torres, S. E. Nicholson, and T. E. Gill (2002), Environmental characterization of global sources of atmospheric soil dust identified with the NIMBUS 7 Total Ozone Mapping Spectrometer (TOMS) absorbing aerosol product, Rev. Geophys., 40(1), 1002, doi:10.1029/2000RG000095.

Raes, F., R. Van Dingen, E. Vignati, J. Wilson, J.-P. Putaud, J. H. Seinfeld, and P. Adams (2000), Formation and cycling of aerosols in the global troposphere, Atmos. Environ., 34, 4215-4540.

Reid, S. J. (1982), An observational study of lee waves using radiosonde data, Tellus, 24, 593-596.

Reisner, J., R. J. Rasmussen, and R. T. Bruintjes (1998), Explicit forecasting of supercooled liquid water in winter storms using the MM5 mesoscale model, Q. J. R. Meteorol. Soc, 124, 1071-1107.

Schoeberl, M. (2004), Extratropical stratosphere-troposphere mass exchange, J. Geophys. Res., 109, D13303, doi:10.1029/2004JD004525.

Schumann, U., J. Ström, R. Busen, R. Baumann, K. Gierens, M. Krautstrunk, F. P. Schröder, and J. Stingl (1996), In situ observations of particles in jet aircraft exhausts and contrails for different sulfur-containing fuels, J. Geophys. Res., 101, 6853-6869.

Scorer, R. S. (1988), Sunny Greenland, Q. J. R. Meteorol. Soc., 114, 3-29. Shapiro, M. (1980), Turbulent mixing within tropopause folds as a mechanism for the exchange of chemical constituents between the stratosphere and troposphere, J. Atmos. Sci., 37, 994-1004.

Shine, K. P., and A. Sinha (1991), Sensitivity of the Earth's climate to height dependent changes in the water vapor mixing ratio, Nature, 354, $382-384$.

Sprenger, M., M. Croci Maspoli, and H. Wernli (2003), Tropopause folds and cross-tropopause exchange: A global investigation based upon ECMWF analyses for the time period March 2000 to February 2001, J. Geophys. Res., 108(D12), 8518, doi:10.1029/2002JD002587.

Stohl, A., and T. Trickl (1999), A textbook example of long-range transport: Simultaneous observation of ozone maxima of stratospheric and North American origin in the free troposphere over Europe, J. Geophys. Res., 104, 30,445-30,462.

Thorncroft, C. D., B. J. Hoskins, and M. E. McIntyre (1993), Two paradigms of baroclinic-wave cycle behavior, Q. J. R. Meteorol. Soc., 199, $17-55$.

Trickl, T., and H. Vogelmann (2004), A powerful widely tunable singlemode laser system for lidar sounding of water vapor throughout the free troposphere, Eur. Space Agency Spec. Publ., ESA SP-561, 175-178.

Trickl, T., O. R. Cooper, H. Eisele, P. James, R. Mücke, and A. Stohl (2003), Intercontinental transport and its influence on the ozone concentrations over central Europe: Three case studies, J. Geophys. Res., 108(D12), 8530, doi:10.1029/2002JD002735.

Wandinger, U., et al. (2002), Optical and microphysical characterization of biomass-burning and industrial-pollution aerosols from multiwavelength lidar and aircraft measurements, J. Geophys. Res., 107(D21), 8125, doi:10.1029/2000JD000202

Wernli, H., and H. C. Davis (1997), A Lagrangian-based analysis of extratropical cyclones. I: The method and some applications, $Q$. J. R. Meteorol. Soc., 123, 467-489.

Wimmers, A. J., et al. (2003), Signatures of tropopause folding in satellite imagery, J. Geophys. Res., 108(D4), 8360, doi:10.1029/2001JD001358.

Wirth, M., A. Tsias, A. Dörnbrack, V. Weiß, K. S. Carslaw, M. Leutbecher, W. Renger, H. Volkert, and T. Peter (1999), Model-guided Lagrangian observation and simulation of mountain polar stratospheric clouds, J. Geophys. Res., 104, 23,971-23,981

Wirth, V. (1995), Diabatic heating in an axisymmetric cut-off cyclone and related stratosphere-troposphere exchange, Q. J. R. Meteorol. Soc., 121, $127-147$

Wirth, V., and J. Egger (1999), Diagnosing extratropical synoptic-scale stratosphere-troposphere exchange: A case study, Q. J. R. Meteorol. Soc., 125, 635-655.

World Meteorological Organization (2000), Statement of guidance regarding how well satellite capabilities meet WMO requirements in several application areas, World Meteorol. Organ. Tech. Doc., TD-992, Geneva, Switzerland.

Zängl, G. (2002), Stratified flow over a mountain with a gap: Linear theory and numerical simulations, Q. J. R. Meteorol. Soc., 128, 927-949.

Zanis, P., et al. (2003), An estimate of the impact of stratosphere-totroposphere transport (STT) on the lower free tropospheric ozone over the Alps using ${ }^{10} \mathrm{Be}$ and ${ }^{7} \mathrm{Be}$ measurements, J. Geophys. Res., 108(D12), 8520, doi.10.1029/2002JD002604.

A. Dörnbrack, G. Ehret, A. Fix, H. Flentje, C. Kiemle, and M. Wirth, Deutsches Zentrum für Luft- und Raumfahrt Oberpfaffenhofen, Institut für Physik der Atmosphäre, Postfach 1116, Oberpfaffenhofen, D-82234 Wessling, Germany. (harald.flentje@dlr.de)

G. Poberaj, Eidgenössische Technische Hochschule, Zürich, Institute for Quantum Electronics, CH-8093 Zürich, Switzerland. 